\title{
Three-Dimensional Quantitative Recognition of Filler Materials Ahead of a Tunnel Face via Time-Energy Density Analysis of Wavelet Transforms
}

\author{
Sheng Zhang ${ }^{1,2} \mathbb{D}$, Liang Zhang ${ }^{1,2, * \mathbb{D}}$, Wenchao $\mathrm{He}^{3}$, Tonghua Ling ${ }^{3, *}$, Zongwei Deng ${ }^{1,2} \mathbb{D}$ and Guihai Fu ${ }^{1,2}$ \\ 1 School of Civil Engineering, Hunan City University, Yiyang 413000, China; zhangsheng@hncu.edu.cn (S.Z.); \\ dengzongwei@hncu.edu.cn (Z.D.); fuguihai@hncu.edu.cn (G.F.) \\ 2 Hunan Engineering Research Center of Structural Safety and Disaster Prevention for Urban Underground \\ Infrastructure, Hunan City University, Yiyang 413000, China \\ 3 School of Civil Engineering, Changsha University of Science \& Technology, Changsha 410114, China; \\ hewenchao1224@163.com \\ * Correspondence: zhangliang@hncu.edu.cn (L.Z.); lingth@csust.edu.cn (T.L.)
}

check for updates

Citation: Zhang, S.; Zhang, L.; He, W.; Ling, T.; Deng, Z.; Fu, G. Three-Dimensional Quantitative Recognition of Filler Materials Ahead of a Tunnel Face via Time-Energy Density Analysis of Wavelet Transforms. Minerals 2022, 12, 234. https://doi.org/10.3390/ $\min 12020234$

Academic Editor: Abbas Taheri

Received: 29 December 2021

Accepted: 31 January 2022

Published: 11 February 2022

Publisher's Note: MDPI stays neutral with regard to jurisdictional claims in published maps and institutional affiliations.

Copyright: (C) 2022 by the authors. Licensee MDPI, Basel, Switzerland. This article is an open access article distributed under the terms and conditions of the Creative Commons Attribution (CC BY) license (https:// creativecommons.org/licenses/by/ $4.0 /)$.

\begin{abstract}
Advanced geological prediction of tunnels has become an indispensable task to ensure the safety and effectiveness of tunnel construction before excavation in karst areas. Geological disasters caused by unfavorable geological conditions, such as karst caves, faults, and broken zones ahead of a tunnel face, are highly sudden and destructive. Determining how to predict the spatial location and geometric size of unfavorable geological bodies accurately is a challenging problem. In order to facilitate a three-dimensional quantitative analysis of the filler material ahead of the tunnel face, a biorthogonal wavelet with short support, linear phase, and highly matching waveform of ground penetrating radar (GPR) wavelet is constructed by lifting a simple and general initial filter on the basis of lifting wavelet theory. A method for a time-energy density analysis of wavelet transforms (TEDAWT) is proposed in accordance with the biorthogonal wavelet. Fifteen longitudinal and horizontal survey lines are used to detect void fillers of different heights. Then, static correction, DC bias, gain, band-pass filtering, and offset processing are performed in the original GPR profile to enhance reflected signals and converge diffraction signals. A slice map of GPR profile is generated in accordance with the relative position of longitudinal and horizontal survey lines in space. The wavelet transform analysis of a single-channel signal of each survey line is performed by adopting the TEDAWT method because of the similar rule of the single-channel signal of GPR on the waveform overlay and the ability of the constructed wavelet basis to highlight the time-frequency characteristics of GPR signals. The characteristic value points of the first and second interfaces of the void fillers can be clearly determined, and the three-dimensional spatial position and geometric sizes of different void fillers can be obtained. Therefore, the three-dimensional visualization of GPR data is realized. Results show that the TEDAWT method has a good practical application effect in the quantitative identification of void fillers, which provides a basis for the interpretation of advanced geological prediction data of tunnels and for the construction decision.
\end{abstract}

Keywords: tunnel construction; filler materials; ground-penetrating radar; wavelet bases; wavelet transform

\section{Introduction}

Infrastructure monitoring during construction and service has made significant progress in recent decades [1-4], benefitting from the rapid advances in sensing techniques [5-7] and signal-processing algorithms [8-10]. As important infrastructure, tunnel construction has attracted much attention in monitoring technology to mitigate geological challenges, such as those from the karst environment, which accounts for $10 \%$ of the environment in the world. The prediction of karst characteristics through advanced monitoring is crucial to reduce the risk of tunnel construction [11-14]. 
The characteristics of karst development are complex, and karsts have different sizes and shapes. Although a ground survey (or borehole survey) along the tunnel axis can provide rough information for the engineering area before tunnel construction, the forecast is insufficient to infer some sudden changes caused by complex terrain, geology, surface vegetation coverage, and other factors in karst areas [15-17]. In addition, karst caves, underground rivers, faults, joint fissures, and water-bearing structures ahead of the tunnel face are concealing, sudden, and destructive [18-20]. If the geological situations ahead of the tunnel face are not detected before excavation, blind excavation may cause great disturbance to some unstable rocks and even result in other serious geological disasters, such as water and mud inrush [21-23]. During the construction process, the longer the exposure time of the tunnel excavation surface, the more serious the rock mass is wetted by groundwater, which reduces the self-stabilizing ability of the rock mass. In addition, the non-standard construction of the tunnel results in the existence of voids behind the tunnel lining. The above situation will more easily result in the deformation and cracking of the tunnel lining structure, and in severe cases, the tunnel vault will collapse. For example, large-scale water and mud inrush occurred more than 70 times during the construction of Yuanliangshan Tunnel in China. The influx of water and mud flooded the tunnel and interrupted the construction process, causing serious loss of equipment and casualties onsite [24]. During the construction of Qinghan Tunnel in Japan, water and mud bursts occurred many times, causing more than 1300 injuries and 30 deaths. The completion period was 10 years later than originally planned [14]. The Sol-an Tunnel, the longest railway tunnel in a karst terrain in South Korea, also suffered multiple water and mud bursts in the tunnel construction, resulting in severe deformation of the supporting structure and surface subsidence [25]. Therefore, the type and scale of the unfavorable geological condition ahead of the tunnel face should be identified to ensure economy, safety, and efficiency during tunnel construction and take actions accordingly.

In recent years, geophysical exploration/monitoring methods, including seismic refraction, electromagnetic, electrical, resistivity, transient electromagnetic, and infrared detection methods, have been utilized to detect karst caves, faults, joint fissures, and water-bearing structures ahead of the tunnel face. Every method has its own advantages, disadvantages, and scopes of application [26-31]. Compared with other methods, the ground penetrating radar (GPR) method uses a mobile antenna to transmit electromagnetic waves to the researched object along the detection surface, then the received signals are displayed on the monitor in real time [32-34]. Thus, the GPR method has the advantages of high resolution, intuitive images, and fast detection speed and has been widely employed in the detection, diagnosis, analysis, and evaluation of various infrastructures in civil engineering.

For the vicinity of the tunnel working surface that is a narrow detection space including busy construction operations, GPR is the best detection equipment for unfavorable geological conditions, such as karst caves, faults, joint fissures, weak fracture zones, and water-bearing structures. GPR has been employed in the advanced geological prediction and detection of tunnels $[35,36]$. From research literature and data, we determine that the detection personnel generally process the GPR signals by using the algorithms of static correction, gain, offset, and filtering included in the GPR software and then analyzed the amplitude, phase, and frequency changes in the GPR profile to infer and explain unfavorable geological bodies [37-39]. However, the analysis software in GPR generally uses Fourier theory that has no time-frequency localized analysis capability. Consequently, GPR signals processed using analysis software cannot present slight changes or discontinuity, which is easy to cause misjudgment in a complex geological environment.

The reflected signals (detected by GPR) mainly consist of direct coupling waves obtained using receiving-transmitting antennas, ground reflected waves, reflected waves caused by discontinuous underground media, and random interference $[40,41]$. They have typical nonstationary and nonlinear attenuation features [42-44]. In addition, the interpretation of GPR data is different from other typical general engineering tasks and is restricted by environmental interference, the complexity of karst development, and the technical 
conditions of interpretation. Therefore, professional knowledge in digital signal processing and interpretation techniques is required during the construction of shape, size, and spatial model of the unfavorable geological body ahead of the tunnel face. The current wavelet transform method developed on the basis of Fourier transform has the characteristics of multiresolution, and it is suitable for analyzing and processing nonlinear and nonstationary signals. For example, wavelet-based methods, with great feature extraction capacity, are common data-processing tools in structural health monitoring [45] and damage detection [46] and have many applications, such as concrete crack detection [47], bolt looseness monitoring [48], corrosion detection [49], debonding monitoring [50], and void detection in concrete-filled steel tubes [51]. Thus, wavelet time-frequency localization analysis enables critical components (e.g., signal threshold denoising, feature extraction, spectrum analysis, waveform prediction, and image recognition) toward good signal interpretation capability for GPR [52-54]. Nevertheless, when the classical wavelet is used to analyze the time-frequency localization of GPR signals, the choice of wavelet bases is not standardized and targeted, and the results of different wavelet bases may change greatly $[55,56]$. Hence, determining how to use the latest signal-processing methods to construct a wavelet basis that is suitable for the analysis of the time-frequency characteristics of GPR signals and for processing the GPR signal by employing wavelet theory is difficult.

In this study, we construct a biorthogonal wavelet basis with short support, linear phase, and highly matching waveform of GPR wavelet on the basis of the lifting wavelet theory framework and then add it to the wavelet analysis toolbox. A method for the time-energy density analysis of wavelet transforms (TEDAWT) is presented using the biorthogonal wavelet. The GPR profiles obtained from 15 longitudinal and horizontal survey lines determine the approximate location of void fillers. Subsequently, the singlechannel signal reflecting the characteristics of the void fillers can be analyzed by using the TEDAWT method combined with the good time-frequency localization properties of wavelet transform. The starting and end points of the void fillers are determined on the basis of the mutation or abnormal position on time-energy density curves. Lastly, the spatial positions of the void fillers are generated in accordance with the correlation of spatial positions of survey lines and the calculation results of mutation positions with different single-channel signals. The three-dimensional visualization of the spatial position and geometric size of the void fillers is realized, which provides a reference for the interpretation of advanced geological prediction data of tunnel engineering and is highly advantageous for the safety and efficiency of onsite construction.

The remaining sections of this paper are proposed in the following manner. The theoretical background of the construction of biorthogonal wavelet basis and the TEDAWT method are introduced in Section 2. Section 3 elucidates the measurement methodology adopted for the experiment. The results and discussion addressed in Section 4 are to prove the validity and reliability of the proposed method. Lastly, the conclusions are shown in Section 5 .

\section{Theoretical Background}

\subsection{Construction of Biorthogonal Wavelet Basis}

Assuming that an initial biorthogonal filter bank is $\{\widetilde{h}, \widetilde{g}, h, g\}$, the vanishing moments of the initial filter function at the decomposition and reconstruction ends are $N$ and $\widetilde{N}$, respectively. From the definition of vanishing moment, the following equations exist [57-59].

$$
\begin{aligned}
& g(z)=(z-1)^{N} q(z) \\
& \widetilde{g}(z)=(z-1)^{\widetilde{N}} \widetilde{q}(z) .
\end{aligned}
$$

After further lifting, new filters $\widetilde{h}^{\text {new }}$ and $g^{\text {new }}$ can be generated. Setting the lifting goal to increase the vanishing moment from $N$ to $\widetilde{N}$, lifting can be regarded as designing 
a suitable lifting operator $s(z)$. Hence, the new filter $g^{\text {new }}$ can be divided by $(z-1)^{N^{\prime}}$, as shown as follows.

$$
\frac{(z-1)^{N} q(z)+h(z) s\left(z^{2}\right)}{(z-1)^{N^{\prime}}}=Q(z) .
$$

Given that $h(1) \neq 0$, the lifting operator $s(z)$ must contain the factor $(z-1)^{N}$. Therefore, the lifting operator $s(z)$ can be defined as follows.

$$
s(z)=(z-1)^{N} U(\mathbf{z}) .
$$

Substituting Equation (3) into Equation (2) produces the following.

$$
Q(z)=\frac{1}{(z-1)^{\Delta N}}\left[q(z)+h(z)(z+1)^{N} U\left(z^{2}\right)\right]
$$

We then obtain the following.

$$
P(z)=q(z)+h(z)(z+1)^{N} U\left(z^{2}\right) .
$$

In accordance with the lifting target requirement of vanishing moment, the above equation is satisfied as follows.

$$
\left.\frac{d^{k} P(z)}{d z^{k}}\right|_{z=1}=0, k=0,1, \cdots, \Delta N-1 .
$$

Suppose the vanishing moments of the main wavelet and its dual wavelet are both three after lifting. The initial filter is a Haar wavelet with a first-order vanishing moment. The scale and dual-scale filter coefficients of the new biorthogonal wavelet filter bank are obtained by using dual and primal lifting of the initial filter and combining with the particle swarm algorithm for optimization search, as shown as follows.

$$
\left\{\begin{array}{l}
\widetilde{h}_{1}=\left\{\frac{-3}{512}, \frac{-3}{512}, \frac{17}{256}, \frac{-7}{256}, \frac{-77}{512}, \frac{83}{512}, \frac{59}{128},\right. \\
\left.\frac{59}{128}, \frac{83}{512}, \frac{-77}{512}, \frac{-7}{256}, \frac{17}{256}, \frac{-3}{512}, \frac{-3}{512}\right\} . \\
h_{1}=\left\{\frac{-1}{16}, \frac{1}{16}, \frac{1}{2}, \frac{1}{2}, \frac{1}{16}, \frac{-1}{16}\right\}
\end{array}\right.
$$

Meanwhile, the coefficients of wavelet and dual-wavelet filters satisfy the following.

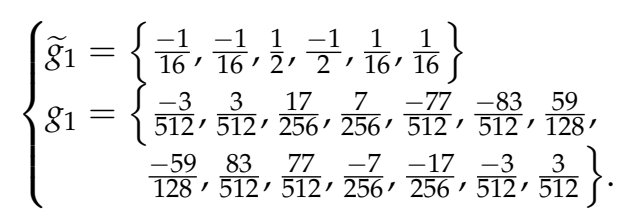

On the basis of the scale filter $h_{1}(z)$ and dual-scale filter $\widetilde{h}_{1}(z)$ obtained above, a new biorthogonal wavelet basis can be constructed.

\subsection{TEDAWT Method}

Assuming a signal function $\psi(t) \in L^{2}(R)\left(L^{2}(R)\right.$ represents a square integrable space), its continuous Fourier transform is $\widehat{\psi}(\omega)$. When $\widehat{\psi}(\omega)$ satisfies the wavelet admissibility condition, the following is obtained:

$$
C_{\psi}=\int_{\mathrm{R}} \frac{|\widehat{\psi}(\omega)|^{2}}{|\omega|} \mathrm{d} \omega<\infty .
$$


where the function $\psi(t)$ is defined as the mother wavelet. If the mother wavelet $\psi(t)$ is stretched and translated, a wavelet basis sequence is obtained.

For the real numbers $a, b$, and $a \neq 0$, the wavelet basis sequence is as follows:

$$
\psi_{a, b}(t)=\frac{1}{\sqrt{|a|}} \psi\left(\frac{t-b}{a}\right),
$$

where $a$ is the stretch factor, and $b$ is the translation factor.

For any signal $f(t) \in L^{2}(R)$, its continuous wavelet transform is as follows.

$$
W_{f}(a, b)=<f(t), \psi_{a, b}(t)>=\frac{1}{\sqrt{|a|}} \int_{\mathrm{R}} f(t) \overline{\psi\left(\frac{t-b}{a}\right)} \mathrm{d} t .
$$

In the equation, $<f(t), \psi_{a, b}(t)>$ represents the inner product of $f(t)$ and $\psi_{a, b}(t)$, and $\overline{\psi\left(\frac{t-b}{a}\right)}$ is the conjugate function of $\psi\left(\frac{t-b}{a}\right)$.

If the biorthogonal wavelet basis constructed above satisfies the admissibility condition of Equation (9), the continuous wavelet transform of the signal is complete, and energy conservation is maintained during the wavelet transform. In accordance with a Moyal inner product theorem, the following equation is given.

$$
\frac{1}{C_{\psi}} \int_{R} \frac{d a}{a^{2}} \int_{R}\left|W_{f}(a, b)\right|^{2} \mathrm{~d} b=\int_{R}|f(t)|^{2} \mathrm{~d} t .
$$

Equation (12) shows that the integral of the square amplitude of the wavelet transform coefficients is proportional to the energy of the analyzed signal. When analyzing nonstationary signals, the instantaneous energy density at a certain point in the time-frequency phase space cannot be known due to the Heisenberg uncertainty principle. Therefore, the instantaneous frequency cannot be known at any given moment. However, in Equatio (12), $\left|W_{f}(a, b)\right|^{2} / C_{\psi} a^{2}$ can be regarded as the energy density function on the time-scale plane, and $\left|W_{f}(a, b)\right|^{2} \Delta a \Delta b / C_{\psi} a^{2}$ can be regarded as the signal energy at stretch factor $a$ and translation factor $b$ at the center, with stretch interval $\Delta a$ and translation interval $\Delta b$. On the basis of the conception of energy density, Equation (12) can be rewritten as follows:

$$
\int_{-\infty}^{+\infty}|f(t)|^{2} \mathrm{~d} t=\int_{-\infty}^{+\infty} E(b) \mathrm{d} b,
$$

where the following is obtained.

$$
E(b)=\frac{1}{C_{\psi}} \int_{0}^{+\infty} \frac{\left|W_{f}(a, b)\right|^{2}}{a^{2}} \mathrm{~d} a .
$$

In a sense, the stretch factor $a$ in wavelet transform indirectly corresponds to the frequency. Therefore, Equation (14) represents the energy distribution of all frequency bands of the signal over time and is called the time-energy density function.

\section{Experimental Methodology}

\subsection{GPR Methodology}

GPR is a nondestructive geophysical detection method without the need for drilling or digging and mainly includes three components, namely, control unit, transmitter, and receiver. The GPR control unit transmits high-frequency electromagnetic waves to the targeted object by using a transmitter. A part of electromagnetic waves becomes reflected when they encounter the targeted object; they then follow the reflection law of electromagnetic waves and transmit to the receiver on the ground due to the differences in relative dielectric constant between the targeted object and the surrounding rock. The control unit 
images the targeted object with different electromagnetic characteristics, and the recorded images are shown on the display of the control unit. Another part of electromagnetic waves penetrates through the targeted objected and spreads underground. Therefore, the detection principle of GPR is to emit electromagnetic waves into the stratum along the object surface via moving the antenna and then measuring the two-way travel time, strength, and energy of the signal reflected from the targeted object. A schematic of GPR detection and imaging is shown in Figure 1, and a schematic of GPR detection on the tunnel face is shown in Figure 2.
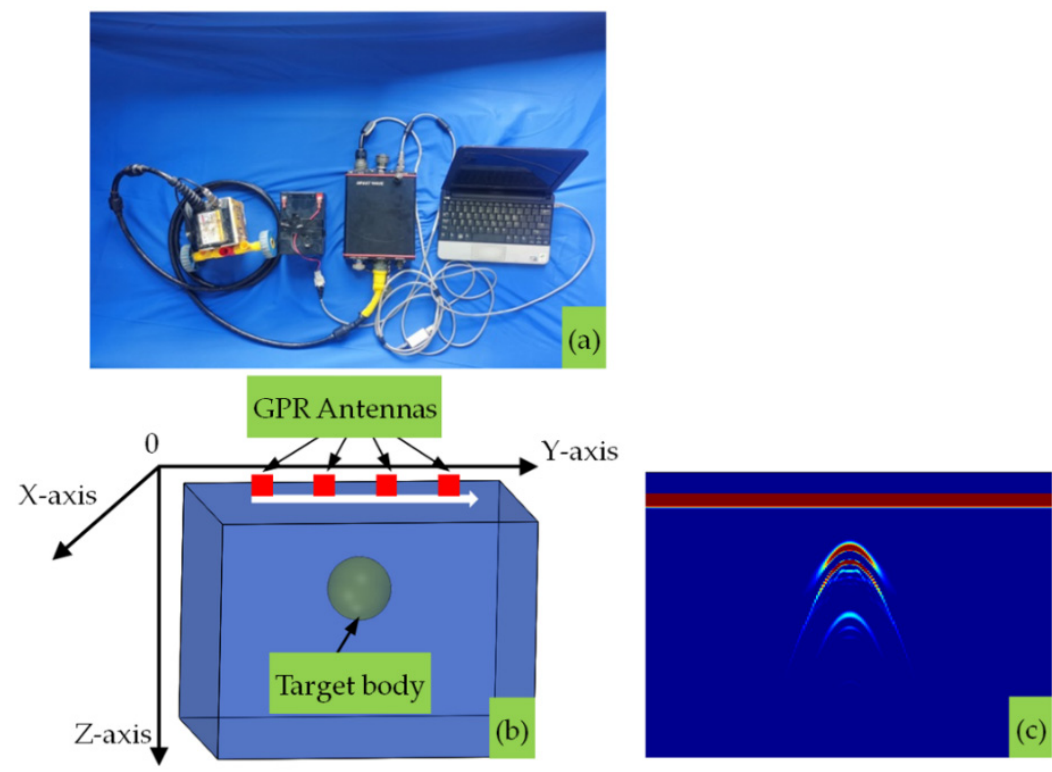

Figure 1. Schematic diagram of GPR detection and imaging. (a) Components of GPR instruments; (b) detection process of underground target body; (c) GPR profile of a survey line.

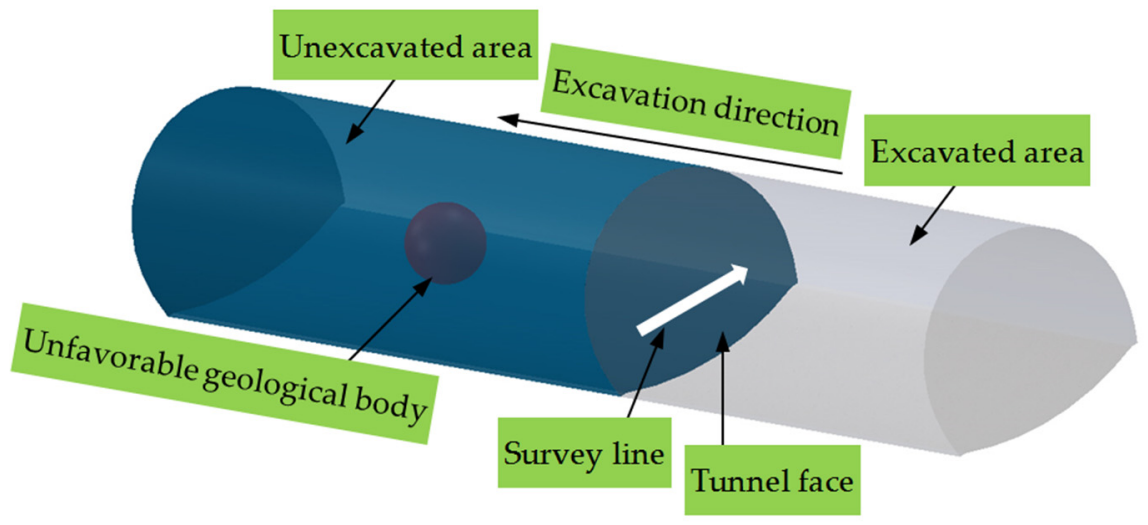

Figure 2. Schematic diagram of GPR detection on the tunnel face.

GPR produces reflection and refraction on the targeted object by using the characteristics of electromagnetic waves through impedance discontinuity, which conforms to the law of reflection and refraction. The energy generated by electromagnetic waves depends on the reflection coefficient $R$ and refraction coefficient $T$ as follows:

$$
\begin{aligned}
& R=\frac{\sqrt{\varepsilon_{1}}-\sqrt{\varepsilon_{2}}}{\sqrt{\varepsilon_{1}}+\sqrt{\varepsilon_{2}}}, \\
& T=\frac{2 \sqrt{\varepsilon_{1}}}{\sqrt{\varepsilon_{1}}+\sqrt{\varepsilon_{2}}},
\end{aligned}
$$


where $\varepsilon_{1}$ and $\varepsilon_{2}$ are the relative dielectric constants of the medium above and below the interface, respectively. Equations (15) and (16) present that the greater the contrast in the relative dielectric constants between the upper and lower media at the interface, the greater the reflection coefficient of electromagnetic waves, and the greater the reflected energy of electromagnetic waves gain. After receiving the GPR signal via the receiving antenna, the control unit of GPR converts the detection signal into a digital signal. The GPR control unit synthesizes the recorded digital signal to a time profile to determine the depth of the targeted object. Subsequently, in accordance with the recorded two-way travel time and the calculated speed, the depth of the targeted object can be calculated as follows:

$$
h=\frac{1}{2} v t,
$$

where $v=c / \sqrt{\varepsilon_{r}}, c$ is the propagation speed of electromagnetic waves in the air $(0.3 \mathrm{~m} / \mathrm{ns})$, and $\varepsilon_{r}$ is the relative dielectric constant of the medium.

From Equation (17), the depth of the targeted object is given by the following.

$$
h=\frac{c t}{2 \sqrt{\varepsilon_{r}}} .
$$

\subsection{Experimental Setup}

An indoor model experiment is one of the most intuitive and reliable research methods. In the model experiment of void fillers, the model size and material are primary elements that affect the results of model experiment. The similarity ratio of the model size should be controlled within 15 to 30 where possible. On the basis of the dimension of tunnel caves, namely, small caves (height less than $1.5 \mathrm{~m}$ ), medium caves (height from $1.5 \mathrm{~m}$ to $3 \mathrm{~m}$ ), and large caves (height more than $3 \mathrm{~m}$ ), the size of the simulated karst cave is set from $5 \mathrm{~cm}$ to $20 \mathrm{~cm}$; four different heights, 5, 10, 15, and $20 \mathrm{~cm}$, are considered; and the length and width are $20 \mathrm{~cm}$. A large amount of yellow mud, wet sand, and other filling media are poured into the tunnel karst caves for real application. In this experiment, empty boxes of different sizes are filled with $25 \%$ moisture content of loess mixture, which is used to simulate void fillers. Figure 3 shows the physical drawings of void fillers with different sizes.

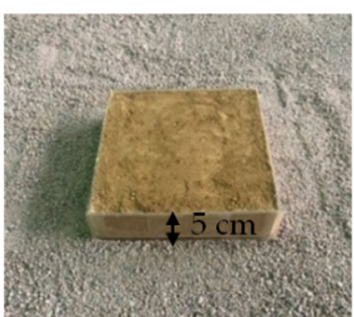

(a)

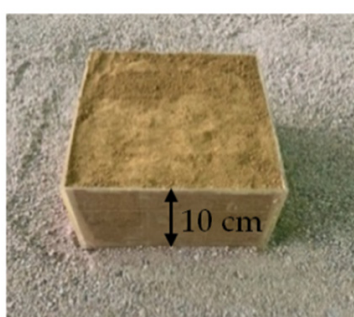

(b)

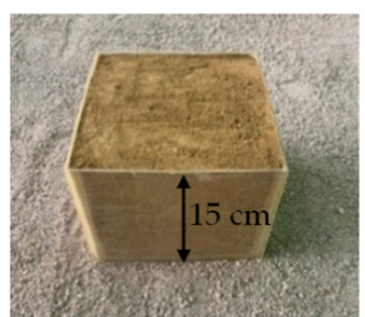

(c)

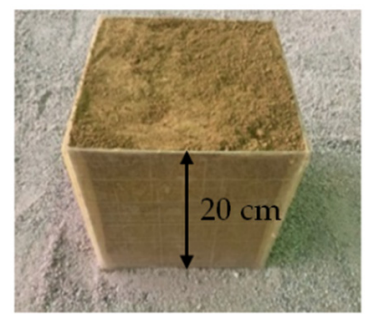

(d)

Figure 3. Physical drawings of void fillers with different sizes: (a) $5 \mathrm{~cm}$ high model box; (b) $10 \mathrm{~cm}$ high model box; (c) $15 \mathrm{~cm}$ high model box; (d) $20 \mathrm{~cm}$ high model box.

The location accuracy of the karst caves ahead of the tunnel face recognized by GPR depends on the propagation speed of electromagnetic waves, that is, the dielectric constant of the surrounding rock. Hence, a material with a similar relative dielectric constant as limestone is chosen to serve as the surrounding medium in the tunnel model experiment. The relative dielectric constant of dry sand is from 4 to 6 and close to that of limestone. Dry sand is also selected in the experiment due to its reusability and low cost. To facilitate the molding of the sand box, the sand box is surrounded by concrete. The length, width, and height are set to 4,3 , and $1.5 \mathrm{~m}$, respectively, to minimize the interference of the concrete boundary on the signal collected by GPR. 
For easy understanding, the horizontal direction is set to the $x$-axis, the $y$-axis is perpendicular to the $x$-axis, and the $z$-axis is vertically downward. The four model boxes are buried along the $y$-axis direction every $0.6 \mathrm{~m}$ from low to high, with a depth of $10 \mathrm{~cm}$ in the sand box. The GPR antenna passes over the model box and marks each detection situation when gathering data. Three longitudinal survey lines, which are denoted as $x_{1}$, $x_{2}$, and $x_{3}$, are arranged perpendicularly to the $x$-axis to describe the three-dimensional size information of void fillers; $x_{2}$ is arranged along the center of the model box; and $x_{1}$ and $x_{3}$ are along the model box's edge layout. Twelve horizontal survey lines are arranged perpendicularly to the $y$-axis, followed by $y_{1}, y_{2}, \ldots, y_{12}$, and the GPR tests of four model boxes in the laboratory are shown in Figure 4.

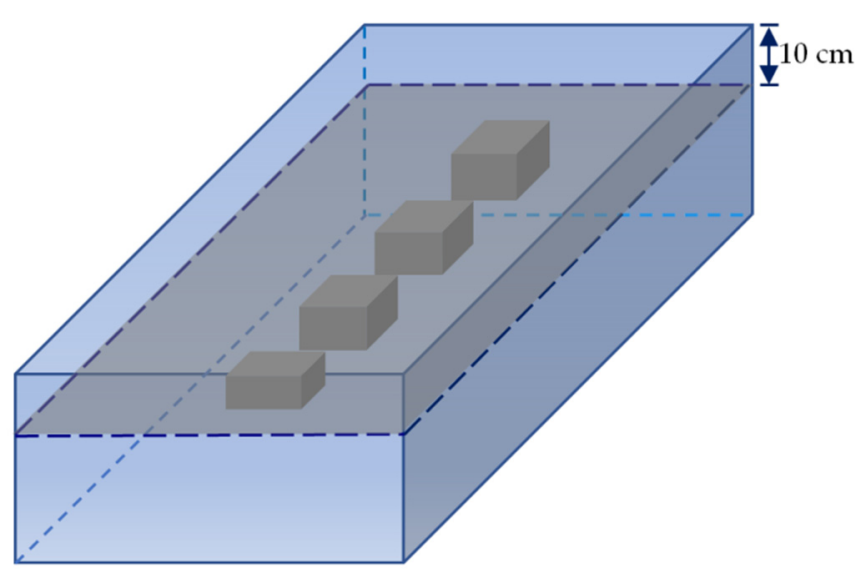

(a)

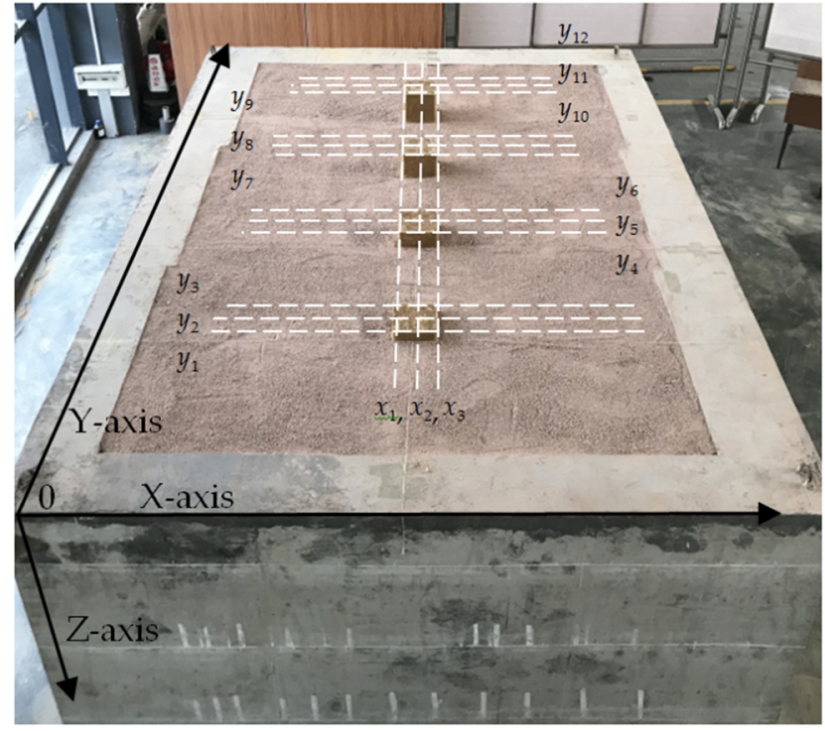

(b)

Figure 4. Indoor experiment of GPR detection: (a) schematic diagram of four model boxes buried in the sand box; (b) fifteen survey lines arranged during GPR testing.

\section{Results and Discussion}

\subsection{GPR Data Collection}

The detection depth of GPR is generally related to the antenna frequency. The lower the frequency of the GPR receiving-transmitting antenna, the greater the detection depth and the lower the resolution; otherwise, the shallower the detection depth, the higher the resolution. Given that the height of the model box is 5, 10,15, and $20 \mathrm{~cm}$ and from previous research experience, a shielded GPR antenna with $1600 \mathrm{MHz}$ center frequency can be used to collect signals. The Ground Probing Radar Systems produced by Ingegneria Dei Sistemi, Italy is selected in the experiment, and each signal collects 384 data points within a $15 \mathrm{~ns}$ sampling time window. Considering that the specific position of void fillers in the sand box is obtained, during the detection process, the signals start to be collected from the sand box boundary at least $0.5 \mathrm{~m}$ to reduce the impact of boundary conditions on the GPR profile. In the horizontal sampling process, a signal is collected every $1 \mathrm{~cm} ; 300$ signals are collected in the longitudinal directions $x_{1}, x_{2}$, and $x_{3}$; and 200 signals are collected in the horizontal directions $y_{1}, y_{2}, \ldots, y_{12}$. Only three longitudinal survey lines and four horizontal survey lines are listed in this paper in consideration of the space limitations. The results are separately shown in Figures 5 and 6. Among them, the red dotted line boxes represent the location of the target body on the GPR time profile. The horizontal direction is the true distance along the GPR survey line in meters; the vertical direction is the two-way travel time of GPR, measured in nanoseconds. 


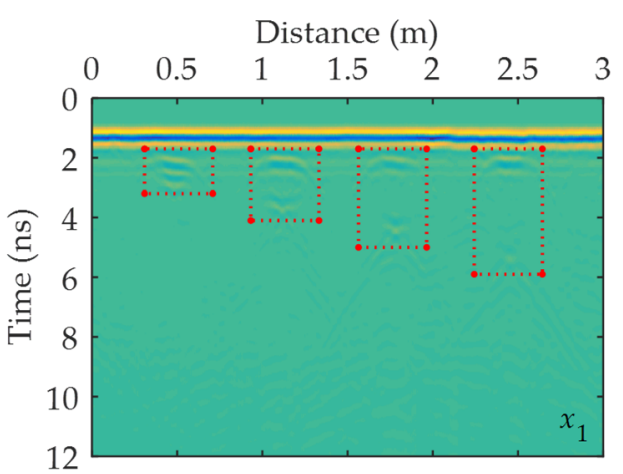

(a)

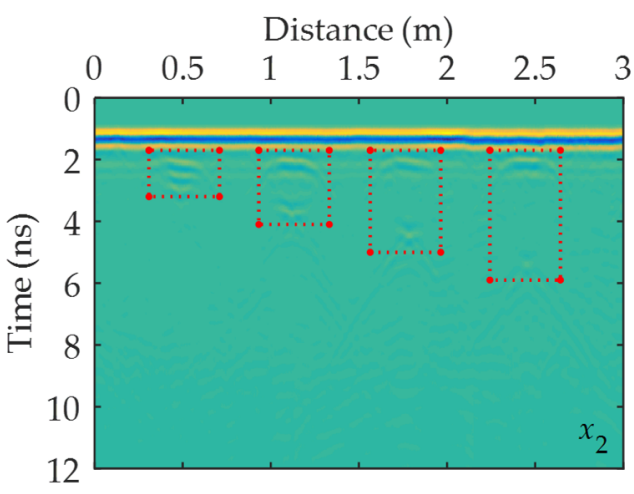

(b)

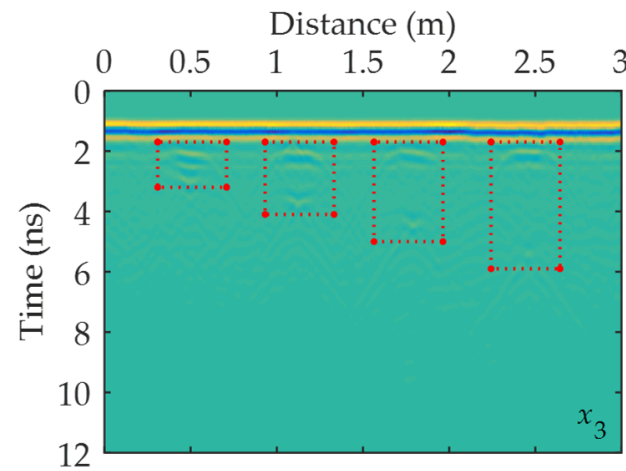

(c)

Figure 5. GPR profiles of three longitudinal survey lines: (a) survey line $x_{1}$; (b) survey line $x_{2}$; (c) survey line $x_{3}$.

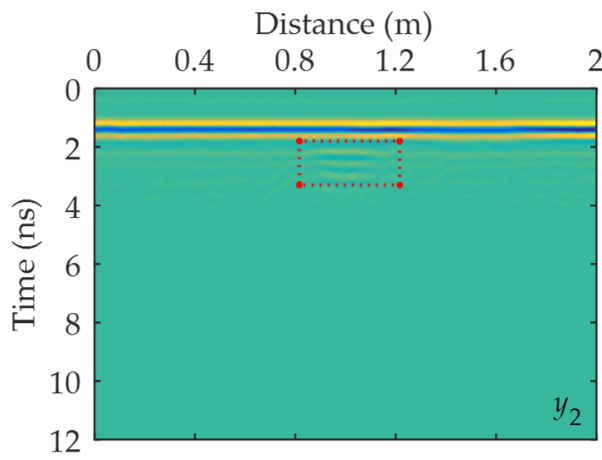

(a)

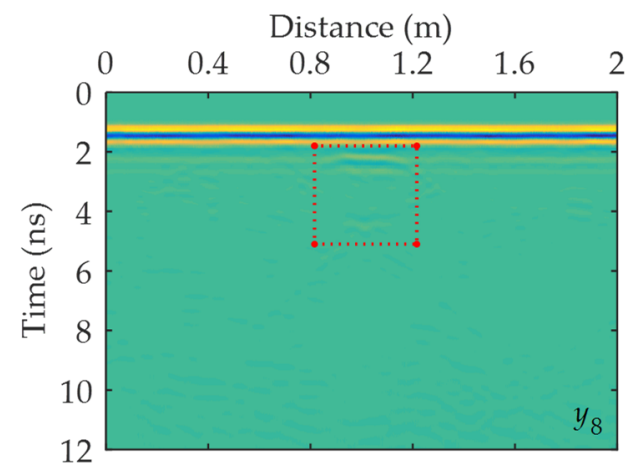

(c)

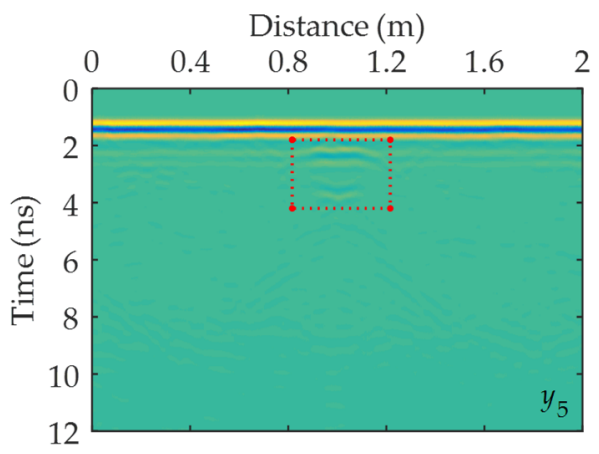

(b)

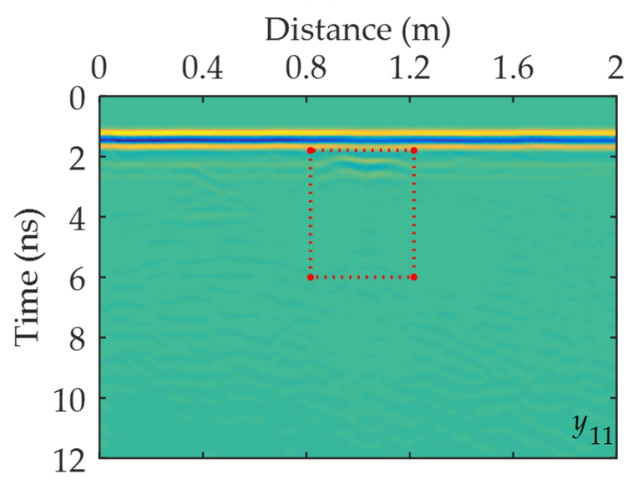

(d)

Figure 6. GPR profiles of four horizontal survey lines: (a) survey line $y_{2}$; (b) survey line $y_{5}$; (c) survey line $y_{8} ;(\mathbf{d})$ survey line $y_{11}$. 
The energy emitted using the GPR transmitting antenna is not limited to vertical propagation into the underground; therefore, it can also be transmitted laterally through the air or the interface between the air and the ground. The energy received by the GPR receiving antenna is mainly interfered by the direct wave between the transmitting and receiving antennas. Thus, the direct wave can be directly used as a zero mark to calculate the depth of object. In addition, the energy received by the GPR receiving antenna comes from the target reflection caused by the impedance discontinuity from shallow to deep. Figures 5 and 6 show that the direct wave reflection of GPR on the surface has strong amplitudes and continuous phases, causing the electromagnetic wave energy to decay rapidly and the deep effective signal to weaken. Hence, the direct wave must be removed to improve the reflection of targeted object via GPR detection.

Each model box occupies a certain width in the direction of the survey line. The GPR antenna collects 200 or 300 single-channel samplings along each survey line from the beginning to the end and then forms a GPR profile. Therefore, the first interface of model boxes in different sizes can be clearly displayed in the GPR profile, and the main feature is a local and discontinuous flat hyperbola. With the increase in the dimension of the model box, the attenuation of electromagnetic waves strengthens, whereas the reflection at the second interface of void fillers weakens. The GPR receiver usually has an ultrawide bandwidth, and the GPR system can easily collect various noises and interferences, resulting in relatively weak reflection signals caused by impedance discontinuities in the stratum. Filtering and migration techniques should be employed to perform signal filtering and enhancement on the original GPR profile to improve the resolution and accuracy of GPR images.

\subsection{Basic Signal Processing}

The original signals shown in Figures 5 and 6 are subjected to static correction, DC bias, gain, band-pass filtering, and offset processing by using the standard analysis software of GPR. The GPR profiles of void fillers are shown in Figures 7 and 8.

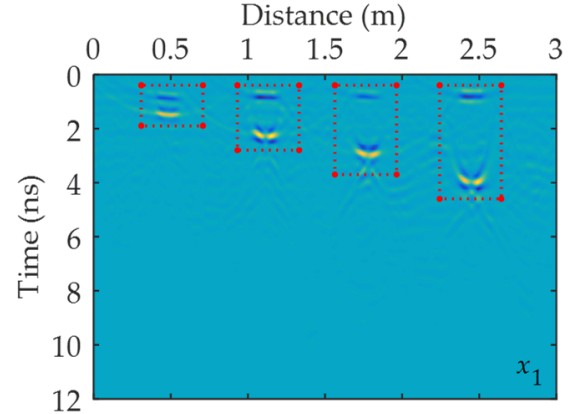

(a)

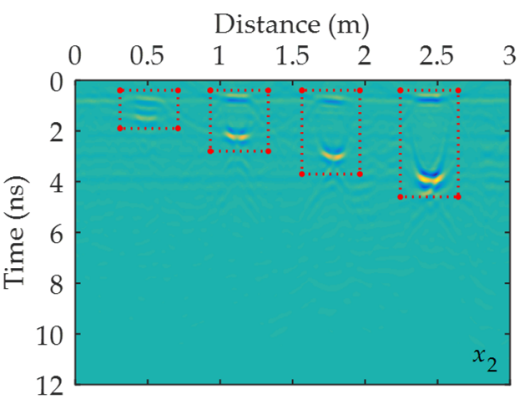

(b)

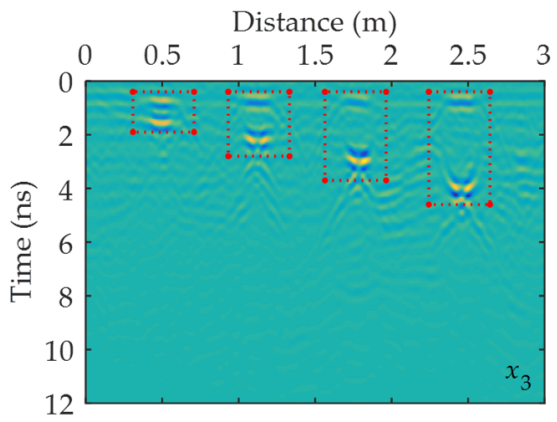

(c)

Figure 7. GPR profiles of three longitudinal survey lines after conventional processing: (a) survey line $x_{1} ;$ (b) survey line $x_{2} ;$ (c) survey line $x_{3}$. 


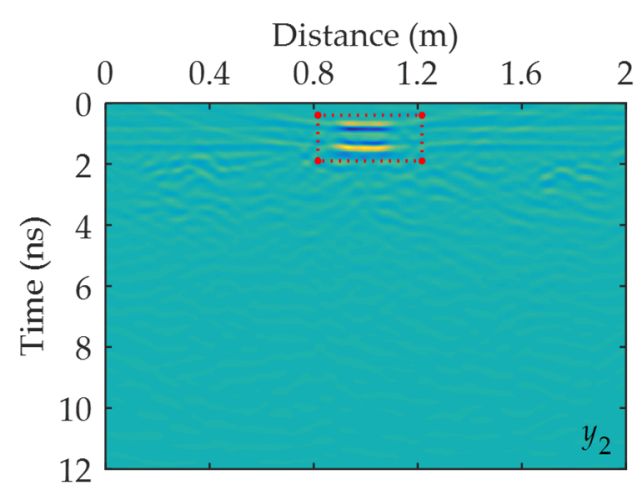

(a)

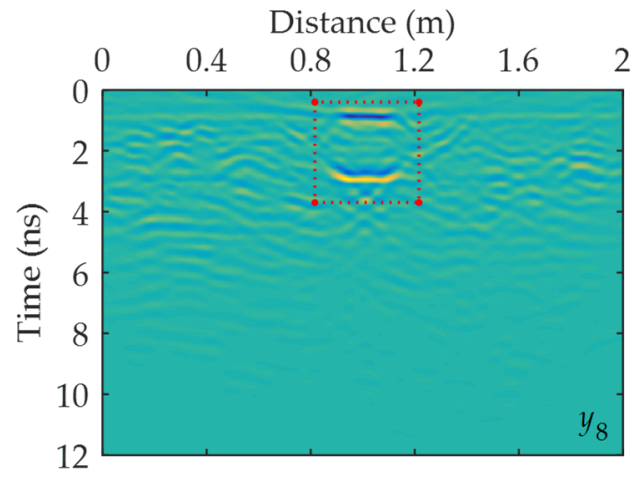

(c)

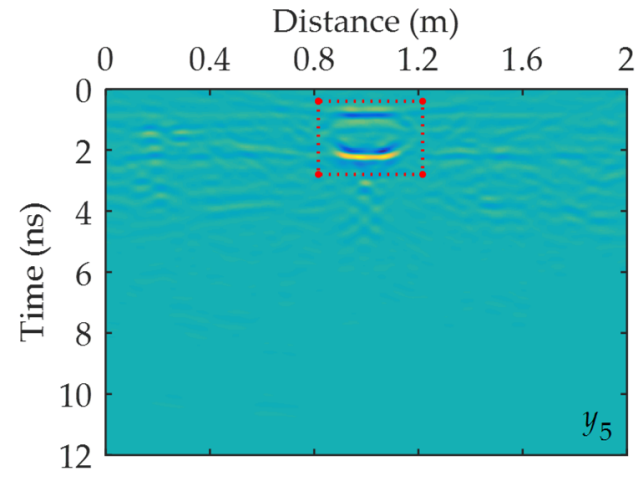

(b)

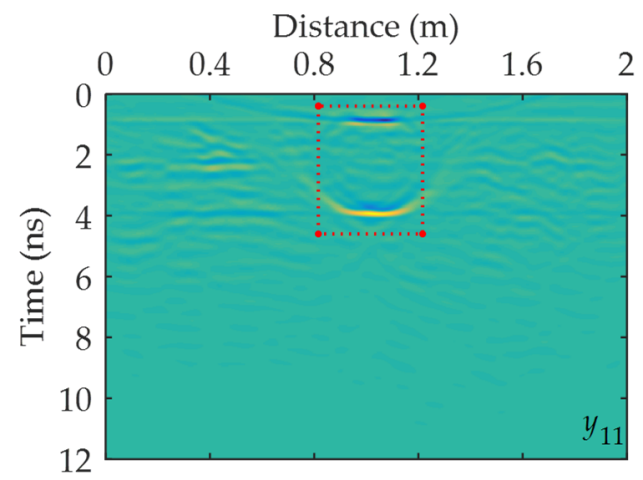

(d)

Figure 8. GPR profiles of four horizontal survey lines after conventional processing: (a) survey line $y_{2} ;(\mathbf{b})$ survey line $y_{5} ;(\mathbf{c})$ survey line $y_{8} ;(\mathbf{d})$ survey line $y_{11}$.

Figures 7 and 8 show that after being processed using the standard software of GPR, the reflection energy of the GPR signal of void fillers is greatly enhanced, the image resolution is significantly improved, and the diffraction waves converge. The reflection of the second interface of void fillers can be determined clearly by comparing with Figures 5 and 6 . Similarly, the same operation process can be performed on eight other GPR data collected using the horizontal survey lines, and the standard-processed GPR profiles can also be obtained. The GPR profiles obtained from three longitudinal survey lines and 12 horizontal survey lines are sliced, and the results are shown in Figures 9 and 10.

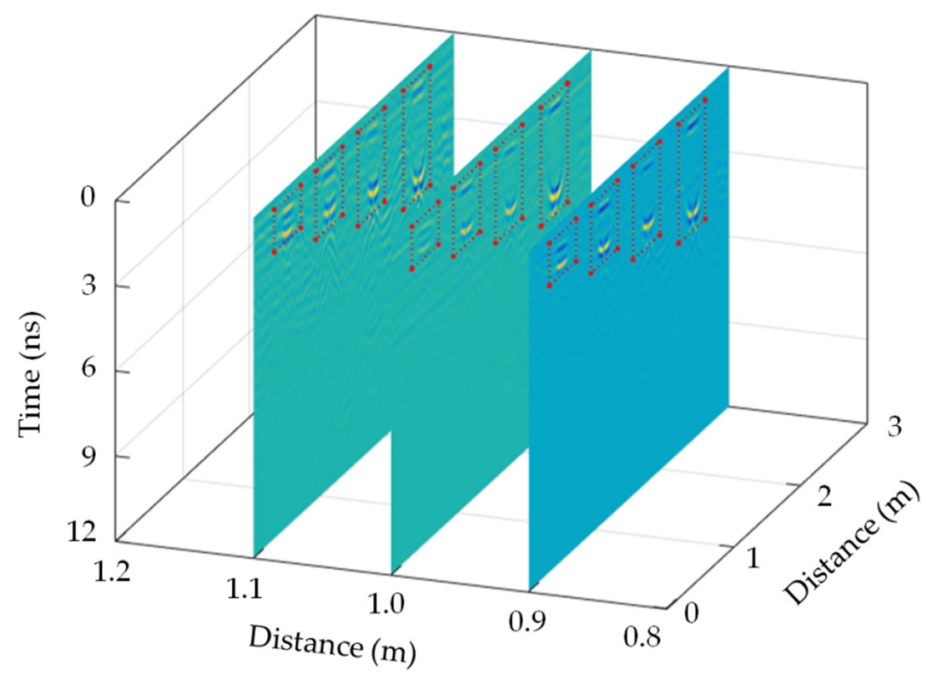

Figure 9. Slice chart formed by three longitudinal survey lines. 


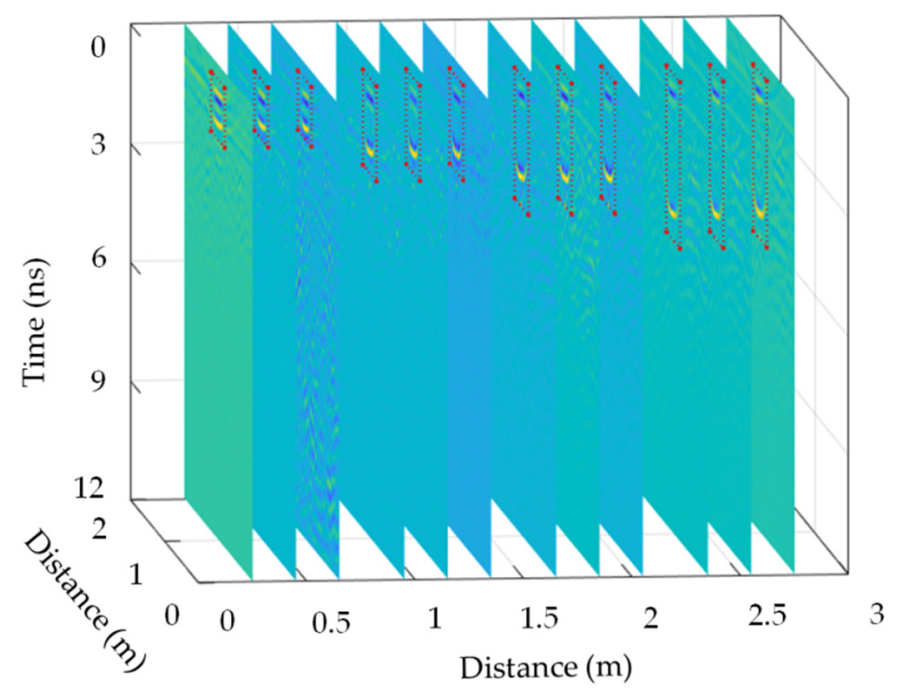

Figure 10. Slice chart formed by twelve horizontal survey lines.

Figures 9 and 10 show that the approximate locations and geometric sizes of void fillers in the sand box are inaccurate. Particularly, when the electromagnetic waves encounter void fillers and are then reflected, it is unclear whether the specific location of the reflection is a crest or a trough. The single-channel signal on every survey line reflects the waveform characteristics of void fillers. The single-channel signals of void fillers should be further analyzed to evaluate the precise position and relative error of void fillers in detail.

\subsection{Time-Energy Density Analysis}

In consideration of the space limitations in this paper, the longitudinal $x_{2}$ line and the horizontal $y_{2}, y_{5}, y_{8}$, and $y_{11}$ lines are used as examples for explanation. The typical single-channel signals reflecting the characteristics of void fillers are extracted from the GPR profile on the longitudinal survey line $x_{2}$ and the horizontal survey lines $y_{2}, y_{5}, y_{8}$, and $y_{11}$. The results are shown in Figures 11 and 12 .

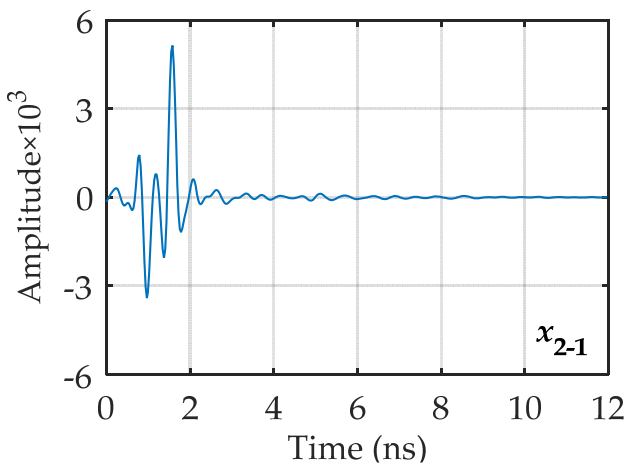

(a)

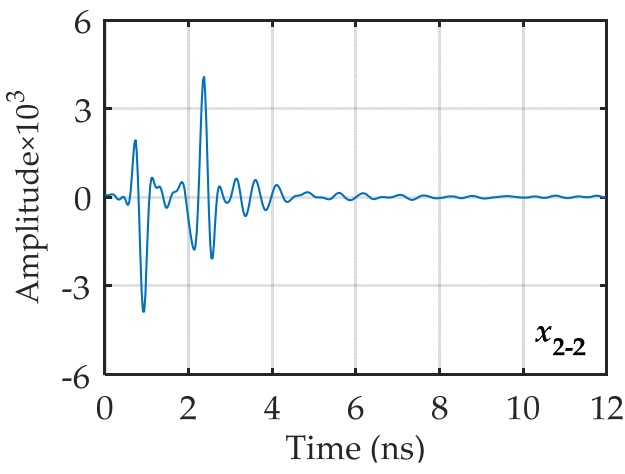

(b)

Figure 11. Cont. 


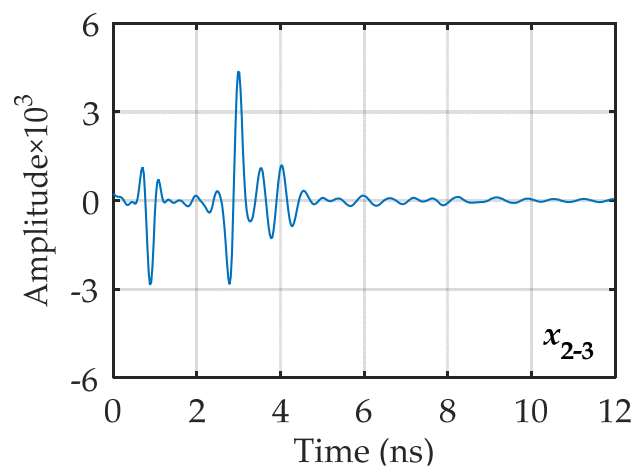

(c)

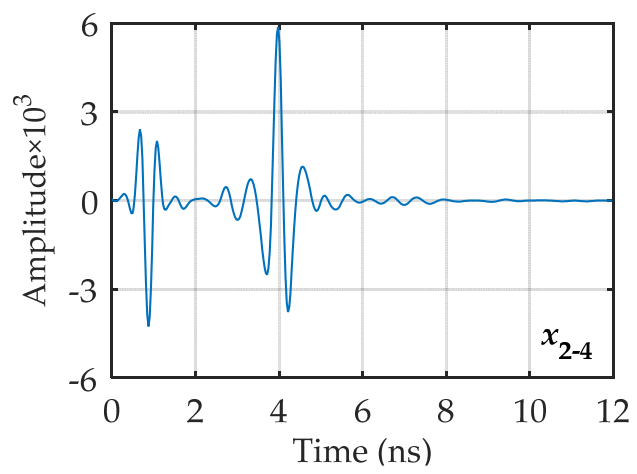

(d)

Figure 11. Different typical single-channel signals on the longitudinal survey line $x_{2}$ : (a) $x_{2-1}$ represents the signal of the $5 \mathrm{~cm}$ model box; (b) $x_{2-2}$ represents the signal of the $10 \mathrm{~cm}$ model box; (c) $x_{2-3}$ represents the signal of the $15 \mathrm{~cm}$ model box; (d) $x_{2-4}$ represents the signal of the $20 \mathrm{~cm}$ model box.

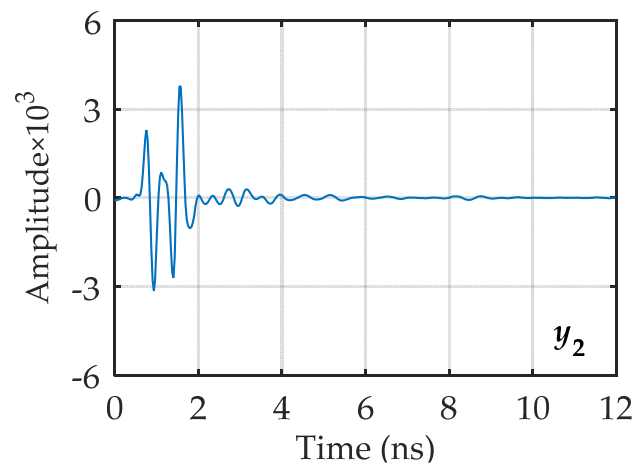

(a)

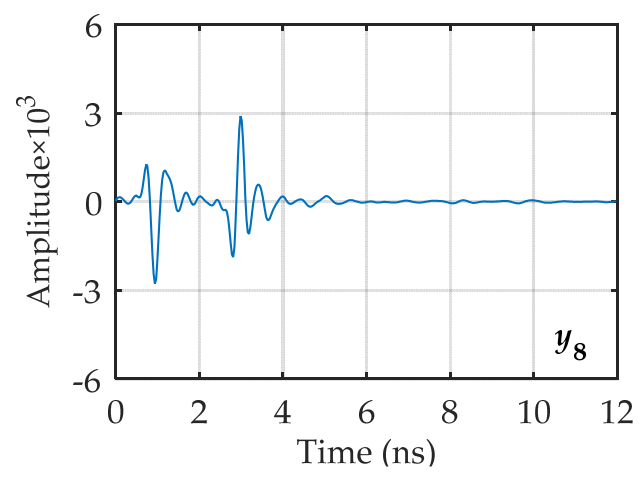

(c)

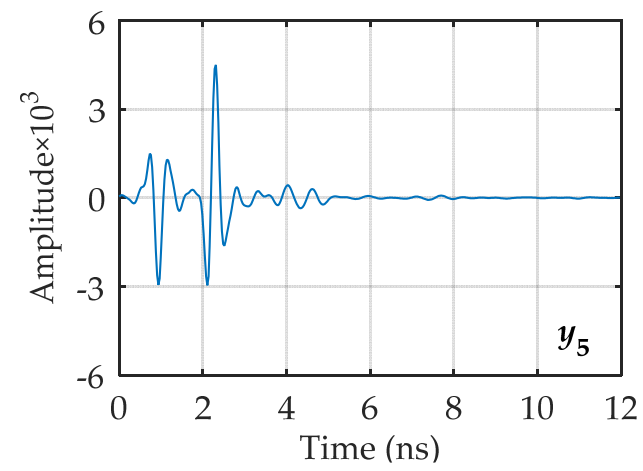

(b)

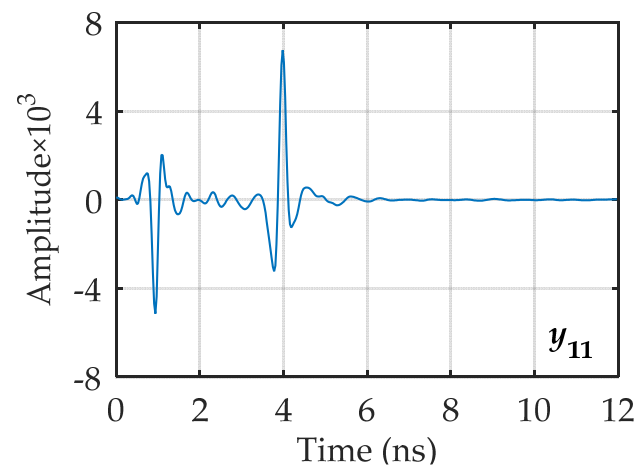

(d)

Figure 12. Different typical single-channel signals on the horizontal survey lines: (a) survey line $y_{2}$; (b) survey line $y_{5} ;$ (c) survey line $y_{8} ;$ (d) survey line $y_{11}$.

Figures 11 and 12 show that the longitudinal and horizontal single-channel signals have a similar attenuation rule on the time axis. The GPR reflection signals of the upper and lower interfaces of the large void filler are clearly separated, while the GPR reflection signals of the upper and lower interfaces of the small void filler are superimposed on each other. That is, as the size of the void filler increases, the GPR reflection signals of the upper and lower interfaces of the void fillers are more clearly separated. Therefore, a single-channel signal can be used as an example for analysis. The biorthogonal wavelet basis constructed above is used as the wavelet basis for wavelet transform. The timeenergy density analysis program for wavelet transform is written in MATLAB, and then 
the different single-channel signals are analyzed using the TEDAWT method. The results are shown in Figures 13 and 14.

Figure 13 shows that the two prominent extreme points on the TEDAWT curves of single-channel GPR signals on the longitudinal survey line $x_{2}$ are two characteristics at the first and second interfaces of void fillers, that is, characteristic points $t_{1}$ and $t_{2}$. The time differences between the two characteristic points are $0.585,1.375,2.107$, and $3.015 \mathrm{~ns}$. Given that the reflection time of GPR detection is a two-way travel time and in accordance with Equation (18), the height values of void fillers are calculated as 4.01, 9.41, 14.43, and $20.64 \mathrm{~cm}$. The relative errors of using this method to identify void fillers are $-19.90 \%$, $-5.86 \%,-3.83 \%$, and $3.21 \%$. From the analysis results of Figure 14, the heights of different void fillers are $3.81,9.02,14.03$, and 20.64 , that is, the relative errors are $-23.87 \%,-9.83 \%$, $-6.48 \%$, and $3.21 \%$, respectively.

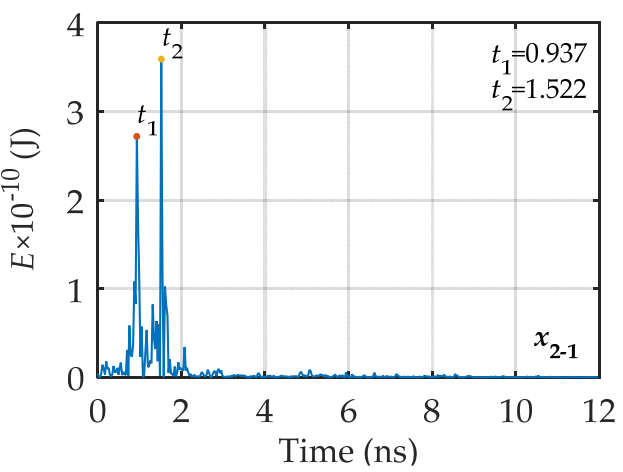

(a)

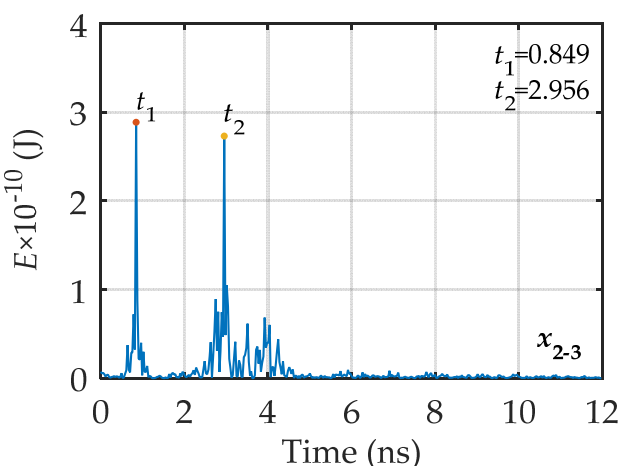

(c)

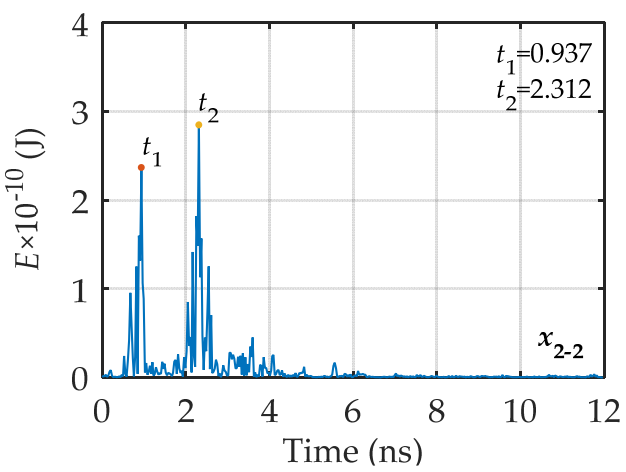

(b)

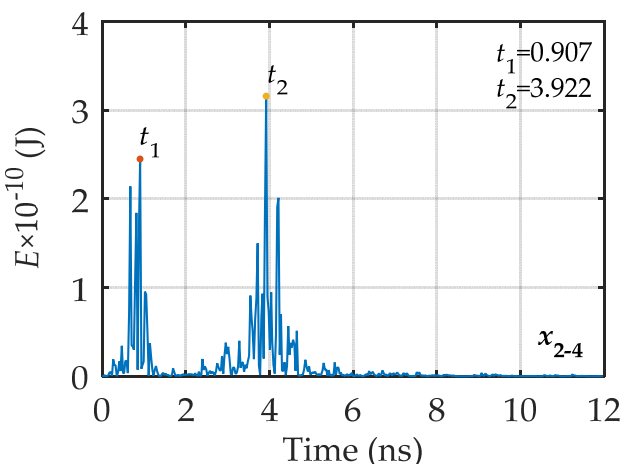

(d)

Figure 13. TEDAWT curves of single-channel signals on the longitudinal survey line $x_{2}$ : (a) $x_{2-1}$ represents the signal of the $5 \mathrm{~cm}$ model box; (b) $x_{2-2}$ represents the signal of the $10 \mathrm{~cm}$ model box; (c) $x_{2-3}$ represents the signal of the $15 \mathrm{~cm}$ model box; (d) $x_{2-4}$ represents the signal of the $20 \mathrm{~cm}$ model box.

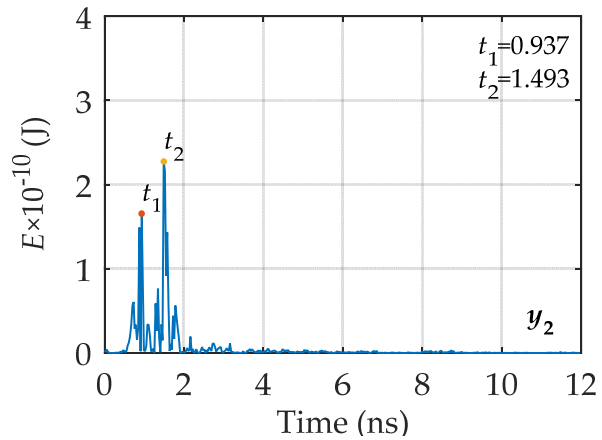

(a)

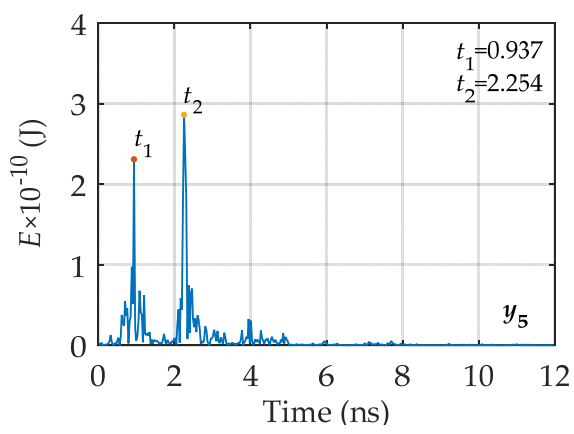

(b)

Figure 14. Cont. 


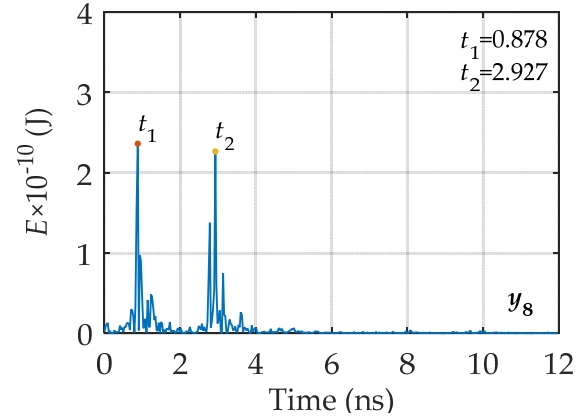

(c)

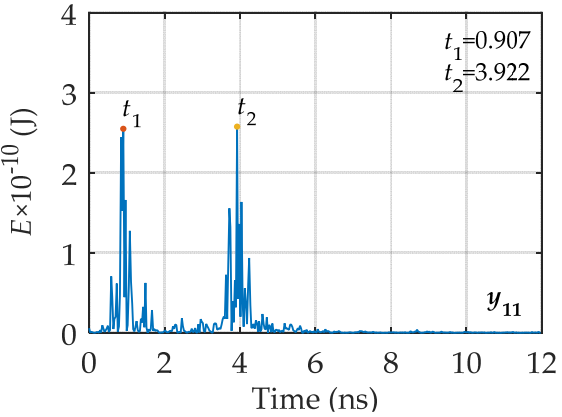

(d)

Figure 14. TEDAWT curves of single-channel signals on the horizontal survey lines: (a) survey line $y_{2} ;(\mathbf{b})$ survey line $y_{5} ;(\mathbf{c})$ survey line $y_{8} ;(\mathbf{d})$ survey line $y_{11}$.

\subsection{Comparative Analysis}

Extensive analysis and research show that the characteristics of wavelet bases of the Daubechies series are good, compact, and supportive and show regularity and smoothness; thus, they are widely used in GPR signal analysis and processing. The following uses $\mathrm{db} 2, \mathrm{db} 4, \mathrm{db} 6$, and db8 wavelet bases to perform wavelet transform on the same signal $y_{2}$ to obtain the modulus curves of wavelet transform coefficients. The results are shown in Figure 15. It can be observed from Figure 15 that, by using different wavelet bases to analyze the same GPR signal, the modulus curves of wavelet transform coefficients obtained are not exactly the same. The time of the first local maximum point is 0.819 , $0.907,0.819$, and 0.761 , respectively. The main reason is that different wavelet bases have different time-frequency localization characteristics. By comparing and analyzing the modulus curves of Figures $14 \mathrm{a}$ and 15, it was observed that the resolution of the modulus curve obtained by using the Daubechies series wavelet bases is poor, and it is difficult to accurately obtain the two modulus maximum points of a GPR signal.

The db5 wavelet basis is employed to perform wavelet transform on the GPR signal on the survey line $y_{2}, y_{5}, y_{8}$, and $y_{11}$, and the modulus curves of wavelet transform coefficient are obtained. The results are shown in Figure 16. Comparing the modulus curves in Figure 16 with the modulus curves in Figure 14, the resolution of the modulus curves obtained by using the db5 wavelet basis is relatively poor; thus, it is difficult to distinguish the first local point in the modulus curves with the second local point (such as Figure 16c,d), which is not beneficial to automatically identify feature points in the modulus curve.

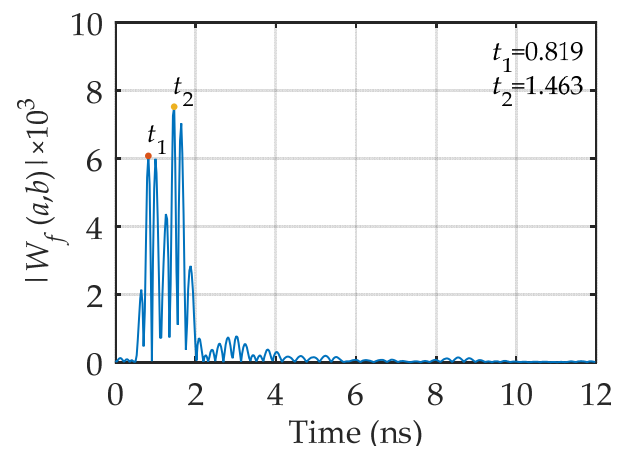

(a)

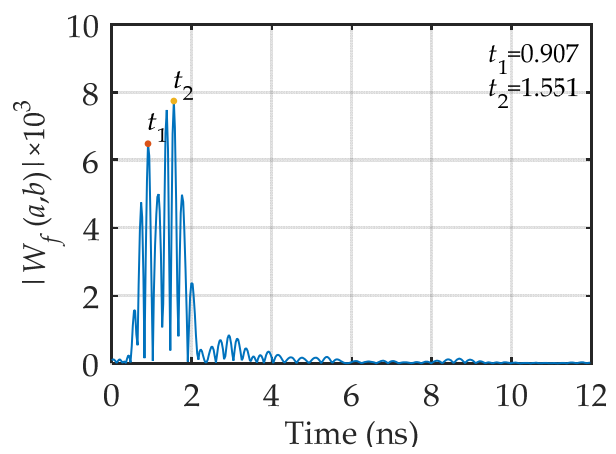

(b)

Figure 15. Cont. 


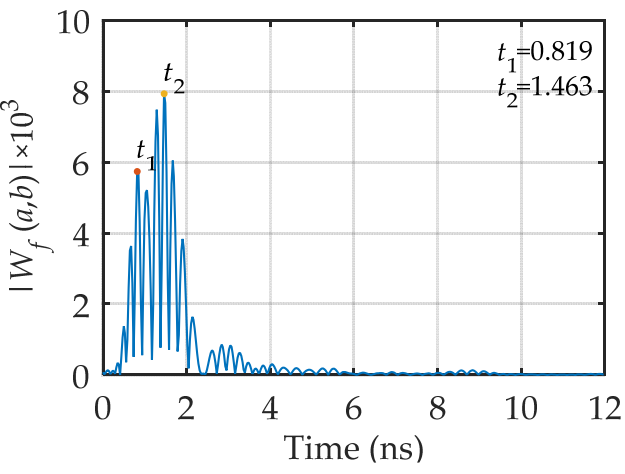

(c)

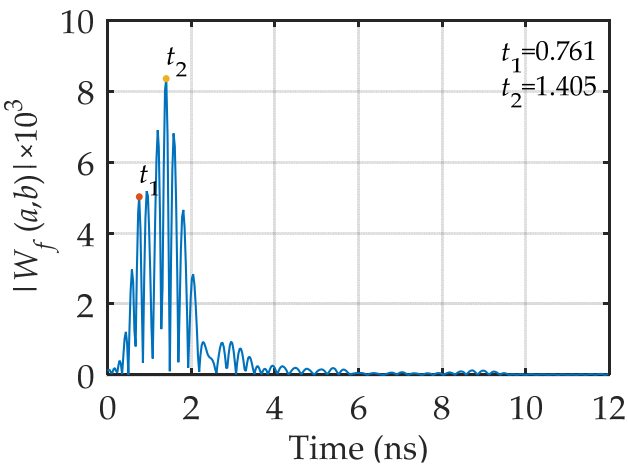

(d)

Figure 15. Modules curves of wavelet transform coefficients obtained by using different wavelet bases for typical single-channel signal on the survey line $y_{2}(a=10)$ : (a) db2 wavelet basis; (b) db4 wavelet basis; (c) db6 wavelet basis; (d) db8 wavelet basis.

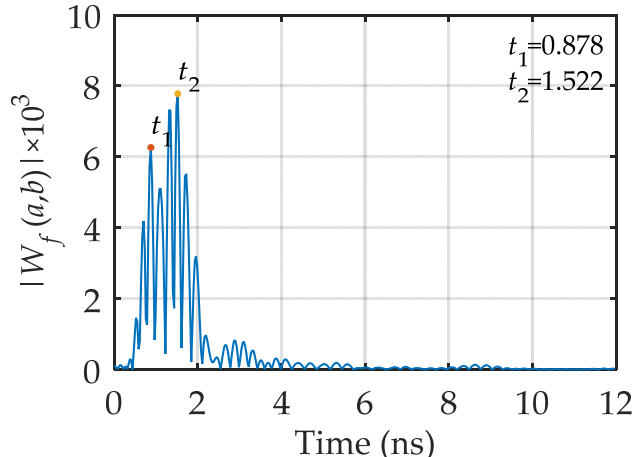

(a)

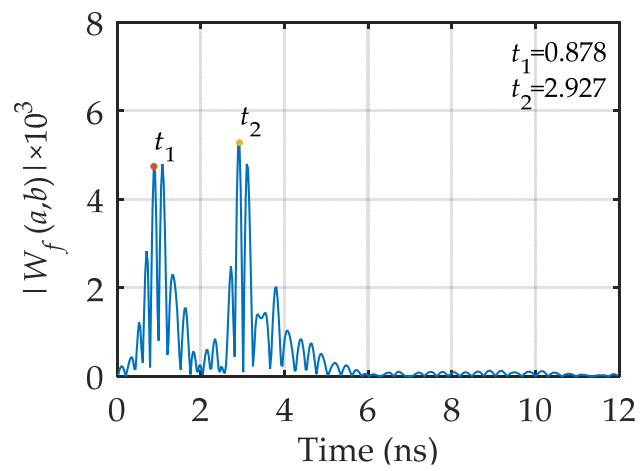

(c)

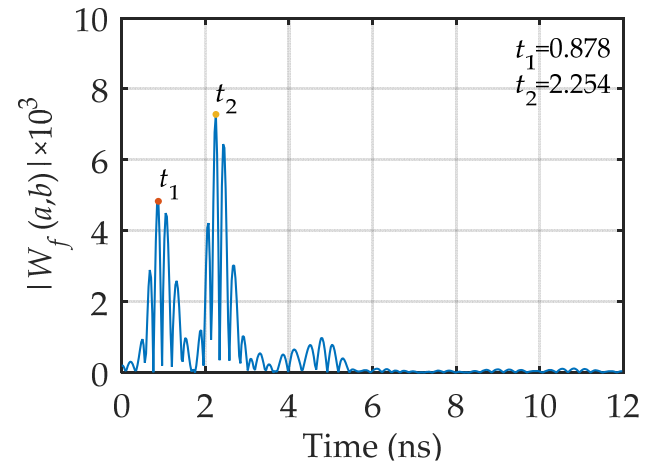

(b)

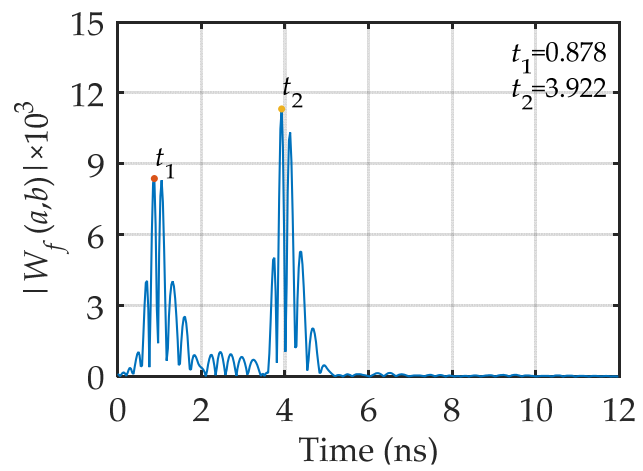

(d)

Figure 16. Modules curves of wavelet transform coefficients obtained by using db5 wavelet basis for typical single-channel signals $(a=10)$ : (a) survey line $y_{2} ;(\mathbf{b})$ survey line $y_{5} ;(\mathbf{c})$ survey line $y_{8}$; (d) survey line $y_{11}$.

When the wavelet transform modulus maximum method is used to analyze the singularity characteristics of a GPR signal, the stretch factor has a great influence on the result of wavelet transform. When the stretch factors are $2,4,6$, and 8 , the db5 wavelet basis is used to perform wavelet transform on the GPR signal on the survey line $y_{2}$, and the modulus curves of wavelet transform coefficients are obtained. The results are shown in Figure 17. It can be observed from Figure 17 that under different stretch scales, the obtained wavelet transform coefficient modulus curves are not completely the same, and the first local maximum points obtained are $0.937,0.995,1.024$, and 0.878 , respectively. Therefore, when performing wavelet transform on the GPR signal, the selected stretch factor is different, and the singularity of GPR signal obtained is also different. Finally, 
compared the modulus curves of Figure 17 with the modulus curves of Figure 14a, the resolution of the curve obtained by the TEDAWT method proposed is higher than the wavelet transform modulus maximum method.

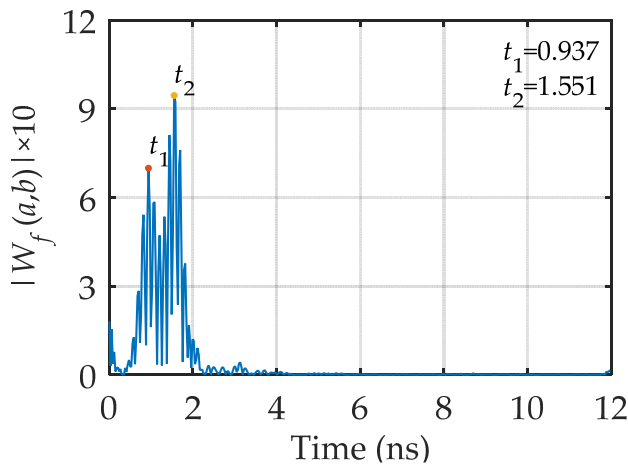

(a)

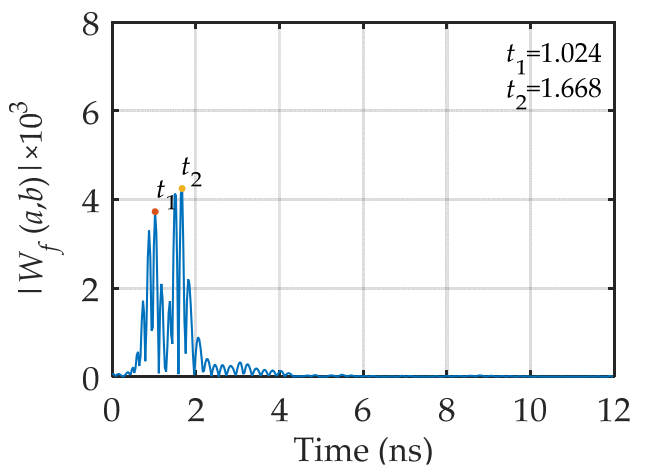

(c)

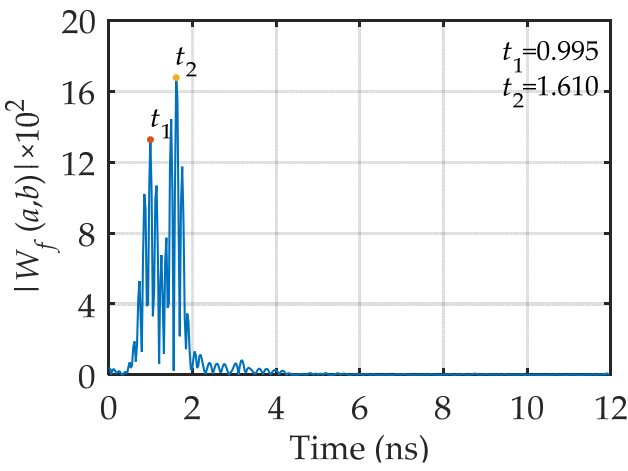

(b)

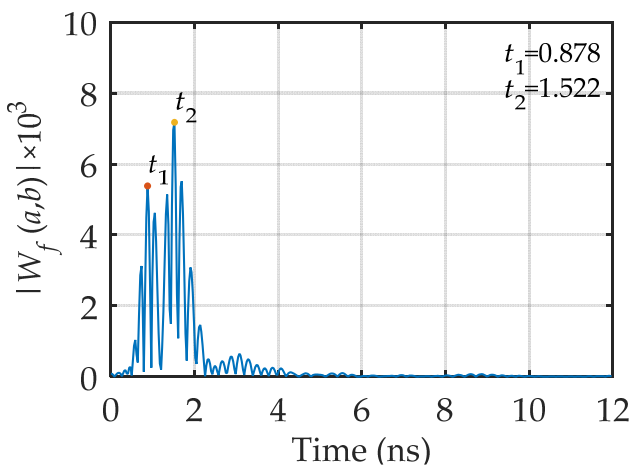

(d)

Figure 17. Modules curves of wavelet transform coefficients obtained by using wavelet transform for typical single-channel signal on the survey line $y_{2}$, under different stretch scales: (a) $a=2$; (b) $a=4$; (c) $a=6 ;$ (d) $a=8$.

\subsection{Quantitative Recognition}

The height values of different void fillers obtained from 480 single-channel signals on each GPR survey line are determined to obtain detailed statistical laws, and the recognition results are plotted in Figure 18.

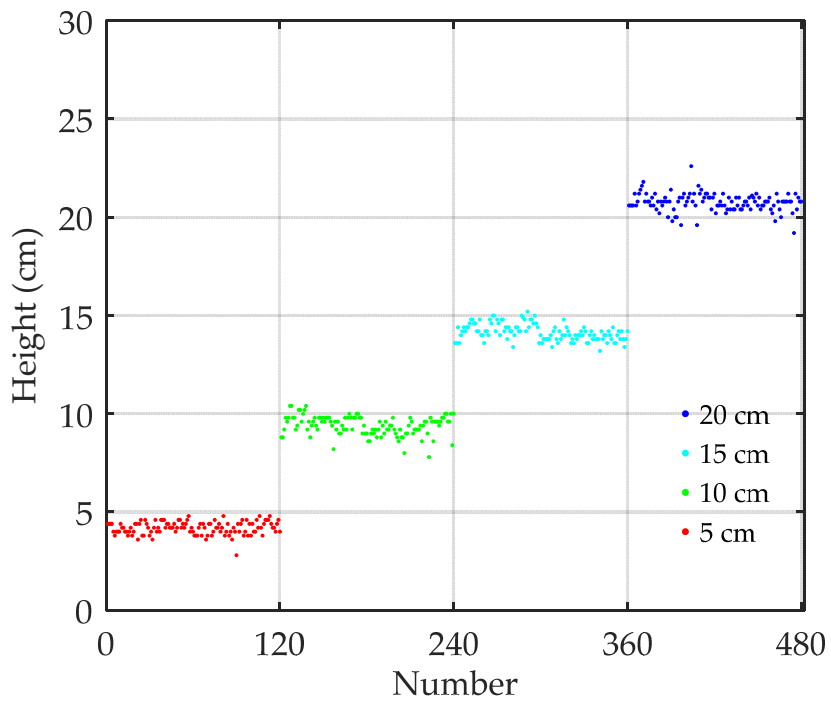

Figure 18. Recognition results with different void fillers. 
Figure 18 shows that the identified height values of void fillers fluctuate by approximately 5, 10, 15, and $20 \mathrm{~cm}$, with average values of 4.20,9.42,14.17, and 20.79 and variances of $0.11,0.24,0.18$, and 0.21 , respectively. The identification errors of void fillers are $-16.09 \%$, $-5.79 \%,-5.54 \%$, and $3.94 \%$. With a continuous increase in the size of the void filler, the identification error is smaller, thus indicating the accuracy of the method proposed in this paper is higher. The extremum points obtained from the first and second interfaces of different void fillers are connected, and the results are plotted in Figure 19.

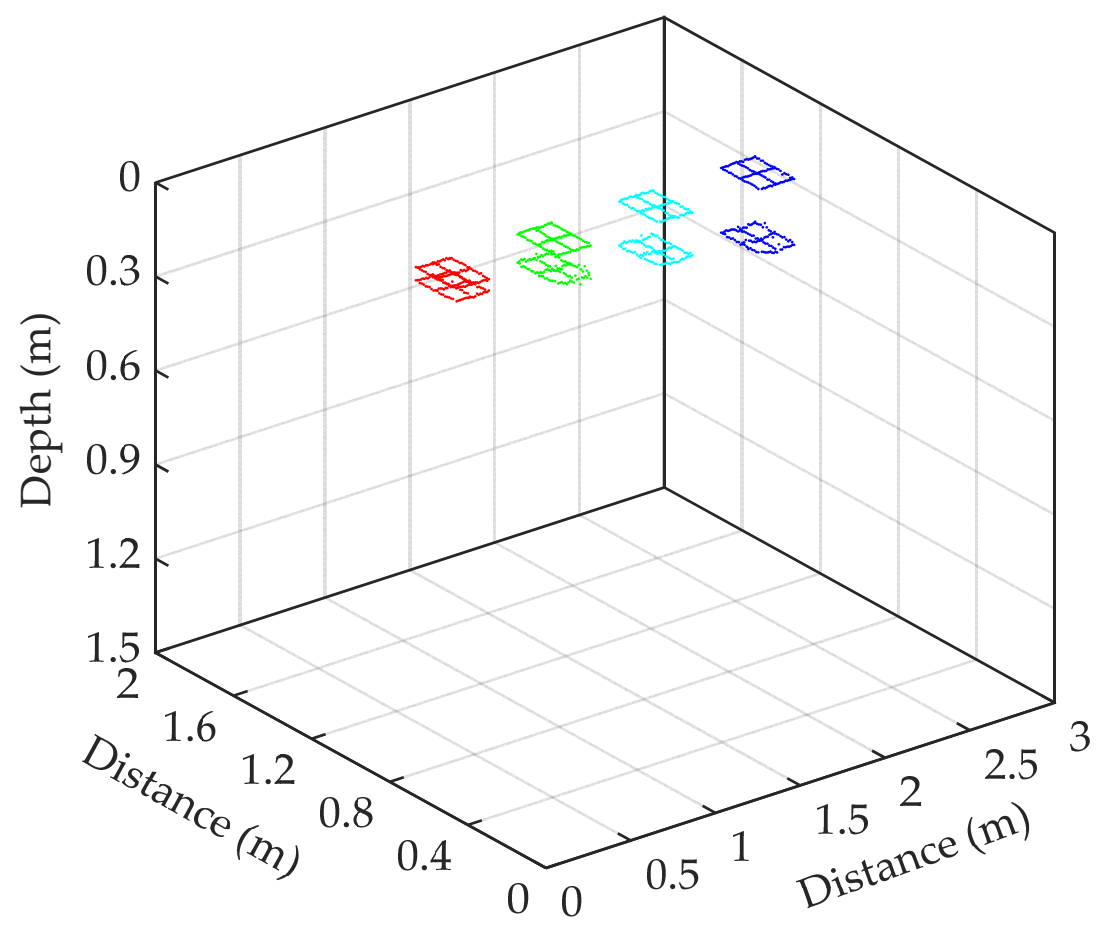

Figure 19. Three-dimensional scatter diagrams formed from the characteristic values of void fillers.

Figure 19 shows that the positions and geometric sizes of void fillers can be obtained on the basis of the relative position of each survey line passing through the void fillers and the height value between the first and second interfaces. Subsequently, connecting the characteristic value points of each filling with a curved surface forms a three-dimensional curved surface diagram. The results are shown in Figure 20, from which the specific positions and geometric sizes of each filling are obtained. Therefore, the TEDAWT method can successfully identify the positions of the first and second interfaces of void fillers at the singular point of GPR signals and then accurately reveal the spatial position and three-dimensional geometry of void fillers in the sand box. It provides a basis for the quantitative identification of unfavorable geological bodies in the advanced geological prediction of tunnels, which is of great significance to the safe and efficient operation of engineering projects. 


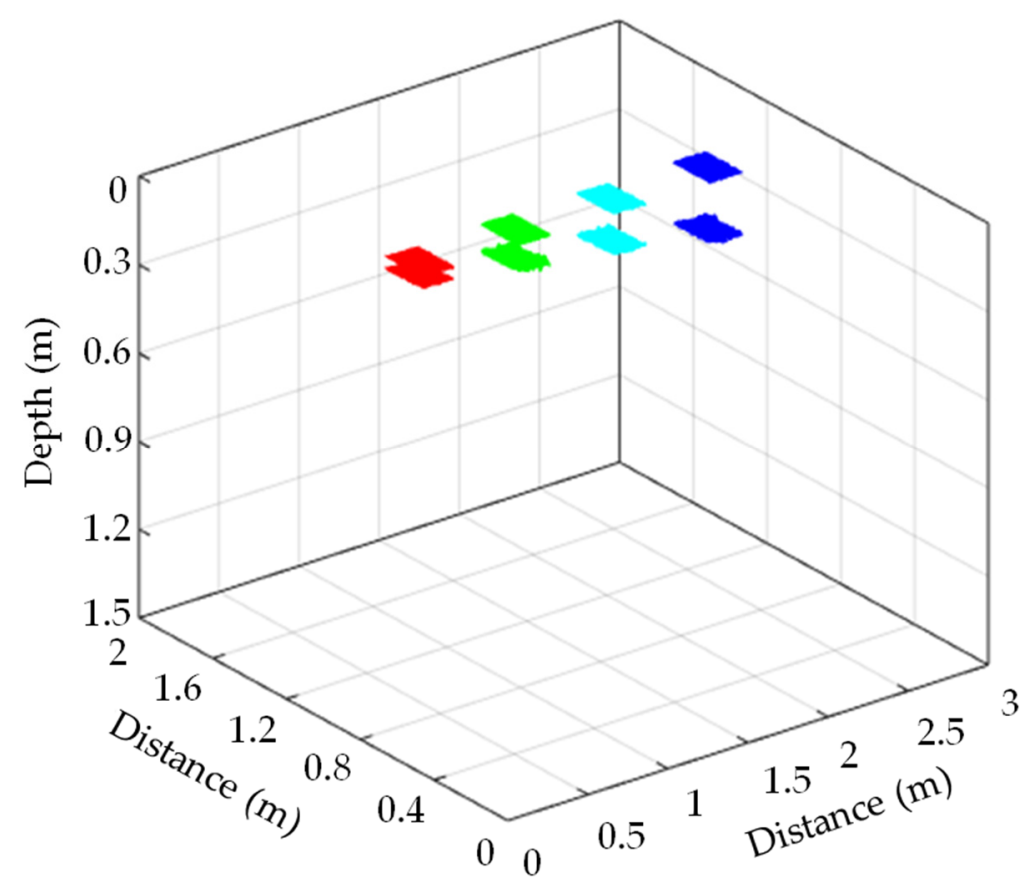

Figure 20. Three-dimensional surface maps formed from the characteristic values of void fillers.

\section{Conclusions}

In this study, a biorthogonal wavelet basis that is short support, linear phase, and highly matching waveform of GPR wavelet was constructed and added to the wavelet analysis toolbox by using the lifting wavelet theory framework. Then, the TEDAWT method was proposed and applied to analyze the mutation or abnormal position of single-channel signals reflecting the characteristics of void fillers. The experimental results demonstrated that the proposed method can effectively determine the spatial position and geometric size of void fillers. The main contributions of this paper are summarized as follows:

(1) Static correction, DC bias, gain, band-pass filtering, and offset processing are performed on the original GPR profile on the basis of the principle of GPR detection to converge the reflected waves of the GPR signal and return the diffracted waves to their positions. The reflections of the second interface can be displayed clearly in the GPR profile. The approximate location and rough shape of void fillers on each survey line can be determined visually by forming the GPR profiles obtained from the longitudinal and horizontal survey lines.

(2) In accordance with a similar rule of single-channel signal of GPR on the waveform overlay, the single-channel signal in the void fillers can be analyzed by using the TEDAWT method, suppressing the interference of random noise. The curve resolution is high, and the characteristic value points of the first and second interfaces of void fillers are determined clearly. In accordance with the characteristic value points obtained using longitudinal and horizontal survey lines, the height values and space sizes of different void fillers are formed, and a three-dimensional visualization of void fillers is realized. As the sizes of void fillers increase, the accuracy of identification by using the TEDAWT method increases. This condition means that the TEDAWT method has good superiority in the detection and analysis of GPR signal singularity.

(3) Forecasting the unfavorable geological conditions, such as faults, karst caves, and weak broken zones ahead of the tunnel face, is helpful to prepare in advance during tunnel excavation. Geological disasters, such as water and mud inrush and collapse caused by blind excavation, can also be avoided. Compared with the two-dimensional profile analysis method of GPR, the three-dimensional visualization method can make a more intuitive judgment on the scale, geometric size, and distribution shape 
of unfavorable geological bodies ahead of the tunnel face to offer convenience and relevant knowledge to onsite construction personnel.

\begin{abstract}
Author Contributions: Conceptualization, T.L. and Z.D.; methodology, S.Z. and L.Z.; software, S.Z., L.Z. and W.H.; validation, L.Z. and T.L.; formal analysis, S.Z.; investigation, S.Z. and W.H.; resources, S.Z., T.L. and Z.D.; data curation, S.Z. and W.H.; writing-original draft preparation, S.Z., L.Z. and W.H.; writing-review and editing, S.Z. and L.Z.; visualization, S.Z. and L.Z.; supervision, T.L.; project administration, S.Z., L.Z., T.L. and G.F.; funding acquisition, S.Z., L.Z., T.L. and G.F. All authors have read and agreed to the published version of the manuscript.
\end{abstract}

Funding: This work was supported by the National Natural Science Foundation of China (Grant Nos. 51608183, 51678071 and 52078061), the Natural Science Foundation of Hunan Province in China (Grant Nos. 2018JJ3022 and 2021JJ50142), and the Outstanding Youth Project of Hunan Provincial Department of Education (Grant No. 21B0725).

Data Availability Statement: All data used to support the findings of this study are included within the article. There are no restrictions on data access.

Acknowledgments: The authors give thanks for the financial support from the National Natural Science Foundation of China (Grant Nos. 51608183, 51678071 and 52078061), the Natural Science Foundation of Hunan Province in China (Grant Nos. 2018JJ3022 and 2021JJ50142), and the Outstanding Youth Project of Hunan Provincial Department of Education (Grant No. 21B0725). The authors also want to thank two anonymous reviewers for their comments and suggestions.

Conflicts of Interest: The authors declare no conflict of interest.

\title{
References
}

1. Benedetto, A.; Tosti, F.; Bianchini Ciampoli, L.; D'Amico, F. An overview of ground-penetrating radar signal processing techniques for road inspections. Signal Process. 2017, 132, 201-209. [CrossRef]

2. Artagan, S.S.; Bianchini Ciampoli, L.; D’Amico, F.; Calvi, A.; Tosti, F. Non-destructive assessment and health monitoring of railway infrastructures. Surv. Geophys. 2019, 41, 447-483. [CrossRef]

3. Degala, S.; Rizzo, P.; Ramanathan, K.; Harries, K.A. Acoustic emission monitoring of CFRP reinforced concrete slabs. Constr. Build. Mater. 2009, 23, 2016-2026. [CrossRef]

4. Drossaert, F.H.; Giannopoulos, A.; Forde, M.C. The detection of abandoned mineshafts by railway track bed using transmitted seismic waves using broadside shot gathers. Constr. Build. Mater. 2018, 183, 88-94. [CrossRef]

5. Li, W.; Kong, Q.; Ho, S.C.M.; Lim, I.; Mo, Y.L.; Song, G. Feasibility study of using smart aggregates as embedded acoustic emission sensors for health monitoring of concrete structures. Smart Mater. Struct. 2016, 25, 115031. [CrossRef]

6. Rhee, J.Y.; Park, K.E.; Lee, K.H.; Kee, S.H. A practical approach to condition assessment of asphalt-covered concrete bridge decks on Korean expressways by dielectric constant measurements using air-coupled GPR. Sensors 2020, 20, 2497. [CrossRef]

7. De Bold, R.; Connolly, D.P.; Patience, S.; Lim, M.; Forde, M.C. Using impulse response testing to examine ballast fouling of a railway trackbed. Constr. Build. Mater. 2021, 274, 121888. [CrossRef]

8. Al-Qadi, I.L.; Xie, W.; Jones, D.L.; Roberts, R. Development of a time-frequency approach to quantify railroad ballast fouling condition using ultra-wide band ground-penetrating radar data. Int. J. Pavement Eng. 2010, 11, 269-279. [CrossRef]

9. Bianchini Ciampoli, L.; Tosti, F.; Brancadoro, M.G.; D’Amico, F.; Alani, A.M.; Benedetto, A. A spectral analysis of groundpenetrating radar data for the assessment of the railway ballast geometric properties. NDT E Int. 2017, 90, 39-47.

10. Zhao, S.; Al-Qadi, I.L. Algorithm development for real-time thin asphalt concrete overlay compaction monitoring using groundpenetrating radar. NDT E Int. 2019, 104, 114-123.

11. Zhang, Q.; Liu, Z.; Tan, J. Prediction of geological conditions for a tunnel boring machine using big operational data. Automat. Constr. 2019, 100, 73-83. [CrossRef]

12. Zhang, K.; Tannant, D.D.; Zheng, W.; Chen, S.; Tan, X. Prediction of karst for tunnelling using fuzzy assessment combined with geological investigations. Tunn. Undergr. Space Tech. 2018, 80, 64-77. [CrossRef]

13. Li, S.; Liu, B.; Xu, X.; Nie, L.; Liu, Z.; Song, J.; Sun, H.; Chen, L.; Fan, K. An overview of ahead geological prospecting in tunneling. Tunn. Undergr. Space Tech. 2017, 63, 69-94. [CrossRef]

14. Ling, T.; Zhang, S.; Li, S. Hilbert-Huang transform method for detection signal of tunnel geological prediction using ground penetrating radar. Chin. J. Rock Mech. Eng. 2012, 31, 1422-1428.

15. Liu, B.; Liu, Z.; Li, S.; Nie, L.; Su, M.; Sun, H.; Fan, K.; Zhang, X.; Pang, Y. Comprehensive surface geophysical investigation of karst caves ahead of the tunnel face: A case study in the Xiaoheyan section of the water supply project from Songhua River, Jilin, China. J. Appl. Geophys. 2017, 144, 37-49.

16. Bu, L.; Li, S.; Shi, S.; Li, L.; Zhao, Y.; Zhou, Z.; Nie, L.; Sun, H. Application of the comprehensive forecast system for water-bearing structures in a karst tunnel: A case study. Bull. Eng. Geol. Environ. 2017, 78, 357-373. [CrossRef] 
17. Kowalczyk, S.; Cabalski, K.; Radzikowski, M. Application of geophysical methods in the evaluation of anthropogenic transformation of the ground: A case study of the Warsaw environs, Poland. Eng. Geol. 2017, 216, 42-55. [CrossRef]

18. Wei, L.; Magee, D.-R.; Cohn, A.-G. An anomalous event detection and tracking method for a tunnel look-ahead ground prediction system. Automat. Constr. 2018, 91, 216-225. [CrossRef]

19. Wei, L.; Khan, M.; Mehmood, O.; Dou, Q.; Bateman, C.; Magee, D.-R.; Cohn, A.G. Web-based visualisation for look-ahead ground imaging in tunnel boring machines. Automat. Constr. 2019, 105, 102830. [CrossRef]

20. Koyan, P.; Tronicke, J. 3D modeling of ground-penetrating radar data across a realistic sedimentary model. Comput. Geosci. 2020, 137, 104422. [CrossRef]

21. Carrière, S.-D.; Chalikakis, K.; Sénéchal, G.; Danquigny, C.; Emblanch, C. Combining electrical resistivity tomography and ground penetrating radar to study geological structuring of karst unsaturated zone. J. Appl. Geophys. 2013, 94, 31-41. [CrossRef]

22. Caselle, C.; Bonetto, S.; Comina, C.; Stocco, S. GPR surveys for the prevention of karst risk in underground gypsum quarries. Tunn. Undergr. Space Tech. 2020, 95, 103137. [CrossRef]

23. Kilic, G.; Eren, L. Neural network based inspection of voids and karst conduits in hydro-electric power station tunnels using GPR. J. Appl. Geophys. 2018, 151, 194-204. [CrossRef]

24. Li, S.; Li, S.; Zhang, Q.; Xue, Y.; Ding, W.; Zhong, S.; He, F.; Lin, Y. Forecast of karst-fractured groundwater and defective geological conditions. Chin. J. Rock Mech. Eng. 2007, 26, 217-225.

25. Song, K.-I.; Cho, G.-C.; Chang, S.-B. Identification, remediation, and analysis of karst sinkholes in the longest railroad tunnel in South Korea. Eng. Geol. 2012, 135-136, 92-105. [CrossRef]

26. Liu, B.; Guo, Q.; Liu, Z.; Wang, C.; Nie, L.; Xu, X.; Chen, L. Comprehensive ahead prospecting for hard rock TBM tunneling in complex limestone geology: A case study in Jilin, China. Tunn. Undergr. Space Tech. 2019, 93, 103045. [CrossRef]

27. Li, S.; Song, J.; Zhang, J.; Wang, C.; Liu, B.; Liu, F.; Ma, S.; Nie, L. A new comprehensive geological prediction method based on constrained inversion and integrated interpretation for water-bearing tunnel structures. Eur. J. Environ. Civ. Eng. 2017, 21, 1441-1465. [CrossRef]

28. Chen, W.; Xue, G.; Olatayo, A.L.; Chen, K.; Khan, M.Y.; Chen, W.; Zhang, L.; Chen, W. A comparison of loop TEM and SOTEM methods for mapping water-enriched zones-A case history in Shaanxi, China. Geophysics 2017, 82, B201-B208. [CrossRef]

29. Zhou, N.; Xue, G. Minimum depth of investigation for grounded-wire TEM due to self-transients. J. Appl. Geophys. 2018, 152, 203-207. [CrossRef]

30. Xue, G.; Li, Z.; Guo, W.; Fan, J. The exploration of sedimentary bauxite deposits using the reflection seismic method: A case study from the Henan Province, China. Ore Geol. Rev. 2020, 127, 103832. [CrossRef]

31. Xue, G.; Zhou, N.; Wang, R.; Liu, H.; Guo, W. Exploration of lead-zinc deposits using electromagnetic method: A case study in Fengtai ore deposits in Western China. Geol. J. 2021, 56, 3314-3321. [CrossRef]

32. Nobes, D.-C. Ground penetrating radar response from voids: A demonstration using a simple model. NDT E Int. 2017, 91, 47-53.

33. De Bold, R.; O'Connor, G.; Morrissey, J.P.; Forde, M.C. Benchmarking large scale GPR experiments on railway ballast. Constr. Build. Mater. 2015, 92, 31-42. [CrossRef]

34. Diamanti, N.; Giannopoulos, A.; Forde, M.C. Numerical modelling and experimental verification of GPR to investigate ring separation in brick masonry arch bridges. NDT E Int. 2008, 41, 354-363.

35. Núñez-Nieto, X.; Solla, M.; Novo, A.; Lorenzo, H. Three-dimensional ground-penetrating radar methodologies for the characterization and volumetric reconstruction of underground tunneling. Constr. Build. Mater. 2014, 71, 551-560. [CrossRef]

36. Li, C.; Wang, L.; Xu, M.; Liu, Y.; Zhong, K.; Zhang, S. Object recognition of ground penetrating radar in karst regions using wavelet energy spectral analysis. Chin. J. Geophys. 2006, 49, 1344-1351. [CrossRef]

37. Zhou, Y.; Chen, W. MCA-based clutter reduction from migrated GPR data of shallowly buried point target. IEEE Trans. Geosci. Remote Sens. 2019, 57, 432-448. [CrossRef]

38. Patriarca, C.; Tosti, F.; Velds, C.; Benedetto, A.; Lambot, S.; Slob, E. Frequency dependent electric properties of homogeneous multi-phase lossy media in the ground-penetrating radar frequency range. J. Appl. Geophys. 2013, 97, 81-88. [CrossRef]

39. Conyers, L.-B.; Sutton, M.-J.; St. Pierre, E. Dissecting and interpreting a three-dimensional ground-penetrating radar dataset: An example from Northern Australia. Sensors 2019, 19, 1239. [CrossRef]

40. Tosti, F.; Bianchini Ciampoli, L.; Calvi, A.; Alani, A.M.; Benedetto, A. An investigation into the railway ballast dielectric properties using different GPR antennas and frequency systems. NDT E Int. 2018, 93, 131-140.

41. Shangguan, P.; Al-Qadi, I.L. Calibration of FDTD simulation of GPR signal for asphalt pavement compaction monitoring. IEEE Trans. Geosci. Remote Sens. 2015, 53, 1538-1548. [CrossRef]

42. Tzanis, A. The curvelet transform in the analysis of 2-D GPR data: Signal enhancement and extraction of orientation-and-scaledependent information. J. Appl. Geophys. 2015, 115, 145-170. [CrossRef]

43. Ling, T.; Zhang, L.; Liu, H.; Gu, D.; Yu, B.; Zhang, S. OMWS method for weak signal processing of GPR and its application in the identification of concrete microcracks. J. Environ. Eng. Geoph. 2019, 24, 317-325. [CrossRef]

44. Ling, T.; Zhang, L.; Huang, F.; Gu, D.; Yu, B.; Zhang, S. OMHT method for weak signal processing of GPR and its application in the identification of concrete micro-crack. J. Cent. South Univ. 2019, 26, 3057-3065. [CrossRef]

45. Hou, Q.; Ren, L.; Jiao, W.; Zou, P.; Song, G. An improved negative pressure wave method for natural gas pipeline leak location using FBG based strain sensor and wavelet transform. Math. Probl. Eng. 2013, 2013, 278794. [CrossRef] 
46. Feng, Q.; Kong, Q.; Huo, L.; Song, G. Crack detection and leakage monitoring on reinforced concrete pipe. Smart Mater. Struct. 2015, 24, 115020. [CrossRef]

47. Feng, Q.; Kong, Q.; Song, G. Damage detection of concrete piles subject to typical damage types based on stress wave measurement using embedded smart aggregates transducers. Measurement 2016, 88, 345-352. [CrossRef]

48. Jiang, T.; Wu, Q.; Wang, L.; Huo, L.; Song, G. Monitoring of bolt looseness-induced damage in steel truss arch structure using piezoceramic transducers. IEEE Sens. J. 2018, 18, 6677-6685. [CrossRef]

49. Huo, L.; Li, C.; Jiang, T.; Li, H. Feasibility study of steel bar corrosion monitoring using a piezoceramic transducer enabled time reversal method. Appl. Sci. 2018, 8, 2304. [CrossRef]

50. Jiang, T.; Kong, Q.; Patil, D.; Luo, Z.; Huo, L.; Song, G. Detection of debonding between fiber reinforced polymer bar and concrete structure using piezoceramic transducers and wavelet packet analysis. IEEE Sens. J. 2017, 17, 1992-1998. [CrossRef]

51. Xu, B.; Zhang, T.; Song, G.; Gu, H. Active interface debonding detection of a concrete-filled steel tube with piezoelectric technologies using wavelet packet analysis. Mech. Syst. Signal Process. 2013, 36, 7-17. [CrossRef]

52. Baili, J.; Lahouar, S.; Hergli, M.; Al-Qadi, I.-L.; Besbes, K. GPR signal de-noising by discrete wavelet transform. NDT E Int. 2009, 42, 696-703.

53. Bai, H.; Sinfield, J.-V. Improved background and clutter reduction for pipe detection under pavement using ground penetrating radar (GPR). J. Appl. Geophys. 2020, 172, 103918. [CrossRef]

54. Ni, S.-H.; Huang, Y.-H.; Lo, K.-F.; Lin, D.-C. Buried pipe detection by ground penetrating radar using the discrete wavelet transform. Comput. Geotech. 2010, 37, 440-448. [CrossRef]

55. Ling, T.; Liu, H.; Gong, S.; Huang, F. Construction and application of a new biorthogonal wavelet basis for a quantitative analysis of GPR signals. J. Appl. Geophys. 2019, 170, 103837. [CrossRef]

56. Javadi, M.; Ghasemzadeh, H. Wavelet analysis for ground penetrating radar applications: A case study. J. Geophys. Eng. 2017, 14, 1189-1202. [CrossRef]

57. Verma, V.S.; Kumar Jha, R. Improved watermarking technique based on significant difference of lifting wavelet coefficients. Signal Image Video Process. 2014, 9, 1443-1450. [CrossRef]

58. Zhang, S.; Zhang, L.; Ling, T.; Fu, G.; Guo, Y. Experimental research on evaluation of soil water content using ground penetrating radar and wavelet packet-based energy analysis. Remote Sens. 2021, 13, 5047. [CrossRef]

59. Li, H.; Wang, Q.; Wu, L. A novel design of lifting scheme from general wavelet. IEEE Trans. Signal Process. 2001, 49, $1714-1717$. 